\title{
Doramectin inhibits glioblastoma cell survival via regulation of autophagy in vitro and in vivo
}

\author{
CHEN CHEN $^{1 *}$, HONGSHENG LIANG ${ }^{2 *}$, RUIRUI QIN $^{1}$, XIN LI $^{1}$, LIWEI WANG $^{1}$, SONGLIN DU $^{1}$,

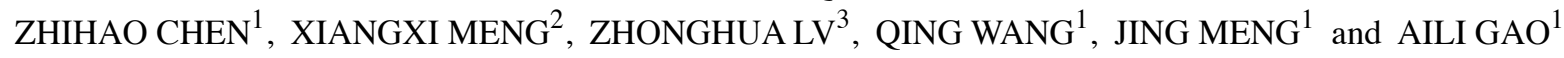 \\ ${ }^{1}$ Department of Bioengineering, College of Life Science, Northeast Agricultural University, \\ Harbin, Heilongjiang 150030; ${ }^{2}$ Department of Neurosurgery, The First Affiliated Hospital of \\ Harbin Medical University, Harbin, Heilongjiang 150001; ${ }^{3}$ Department of Neurosurgery, \\ Harbin Medical University Cancer Hospital, Harbin, Heilongjiang 150081, P.R. China
}

Received February 6, 2021; Accepted September 21, 2021

DOI: $10.3892 / \mathrm{ijo} .2022 .5319$

\begin{abstract}
Glioblastoma (GBM) is one of the most widespread and lethal types of cancer. However, there are currently no drugs or therapeutic strategies that can completely cure GBM. Doramectin (DRM) has a broad range of activities against endoparasites and ectoparasites, and is extensively used in livestock. In the present study, the effect of DRM on the induction of autophagy in U87 and C6 GBM and glioma cell lines, as well as the mechanism of autophagy, were examined. First, transmission electron microscopy, plasmid transfection and western blot analysis demonstrated that DRM could induce autophagy in U87 and C6 cells in vitro. Next, MTT and colony formation assays revealed that DRM-induced autophagy prevented U87 and C6 cell viability and colony formation ratio. In addition, DRM-induced autophagy promoted U87 and C6 cell apoptosis, as indicated by DAPI analysis and flow cytometry. Furthermore, transcriptome analysis demonstrated that DRM modulated a number of genes and pathways involved in autophagy. In a nude mouse xenograft model, immunohistochemical staining and the TUNEL assay demonstrated that the effect of DRM on the tumor was consistent with that in vivo. These data indicated that DRM induced autophagy mainly by blocking the PI3K/AKT/mTOR signaling pathway in GBM cells. DRM-induced autophagy promoted the inhibition of GBM cell proliferation and apoptosis in vitro and in vivo. The present study suggested that DRM may be an effective drug for the treatment of GBM.
\end{abstract}

Correspondence to: Professor Aili Gao, Department of Bioengineering, College of Life Science, Northeast Agricultural University, 600 Changjiang Road, Xiangfang, Harbin, Heilongjiang 150030, P.R. China

E-mail: gaoaili@neau.edu.cn

*Contributed equally

Key words: glioblastoma, autophagy, transcriptomic analysis, PI3K/AKT/mTOR, apoptosis

\section{Introduction}

Glioblastoma (GBM), the most common type of human primary brain tumor, accounts for $81 \%$ of malignant tumors in the central nervous system $(1,2)$. GBM has been classified by World Health Organization as a grade IV glioma and it has a high recurrence rate $(3,4)$. In a Swiss population-based study, the survival rate of patients with newly diagnosed GBM was $\sim 18 \%$ at 1 year and only $3 \%$ at 2 years $(5,6)$. Despite the availability of state of the art multimodality treatments, the median survival of GBM patients is $12-15$ months $(7,8)$. The current treatments for GBM include neurosurgical resection, radiotherapy and pharmacotherapy $(9,10)$. However, these therapies fail tosuccessfully treat GBM due to various reasons (11). One of the main reasons is the high tendency of the tumor to invade the surrounding healthy brain tissues (12). Another reason is the multi-drug resistance encountered during GBM chemotherapy (13). Therefore, there is an urgent need for novel and/or improved drugs or treatments to improve the survival of patients with GBM.

Doramectin (DRM) is a genetically modified avermectin (AVM), which is produced by actinomycetes (fungi) and has potent anthelmintic and insecticidal activities $(14,15)$. DRM is one of the most widely used macrocyclic lactone endo/ectoparasiticides worldwide (16). It has been demonstrated that DRM could reverse the multidrug resistance of cancer cells (17). In addition, it has been reported that macrocyclic lactones are well-tolerated agents, which are used to treat a large number of animals for parasitic infections $(18,19)$. Macrocyclic lactone endo/ectoparasiticides have also been demonstrated to suppress certain activities in human cancer cells (20). For instance, certain studies, including our previous study, have revealed that ivermectin (IVM) and AVM induce apoptosis and autophagy in glioma, HeLa and Ehrlich carcinoma cells (21-23). DRM is a third-generation derivative of the AVM class of macrolides. Unlike AVM, it has a cyclohexyl group in the C25 position of the AVM ring (Fig. 1). In addition, DRM is absorbed more quickly, and has a longer lasting effect and plasma half-life in animals compared with IVM and AVM (24). Therefore, it was hypothesized that DRM may have similar effects on cancer cells and may be a superior anticancer drug compared with existing anticancer drugs. 
Programmed cell death has attracted considerable attention from researchers as a tumor suppression mechanism $(25,26)$. This biological process emerged during anticancer therapies, such as radiation, chemotherapy and certain targeted therapies (27). There are two main morphologically distinctive forms of programmed cell death. Apoptosis and autophagy $(28,29)$. Autophagy is a highly conserved mechanism of eukaryotic cells that serves essential roles in development, tissue homeostasis and diseases (30). A number of studies have suggested that enforced overactivation of autophagy will lead to cell death in certain contexts. For instance, excessive endoplasmic reticulum-specific autophagy mediated by the autophagy receptor FAM134B results in cell death in HeLa cells (31) and SH003 activates autophagic cell death by activating ATF4 and inhibiting G9a under hypoxia in gastric cancer cells (32).

It is well known that autophagy is characterized by the formation of double-membrane vesicles, called autophagosomes (33). In addition, a large number of studies have demonstrated that autophagy can inhibit glioma growth $(34,35)$. However, the effects and mechanisms of DRM in inducing autophagy in GBM cells remain unclear.

The aim of the present study was to explore the roles of DRM in inducing autophagy in GBM cell lines cultured in vitro and in vivo, and to analyze the potential mechanisms of the observed effects using proteomics analysis. In addition, the present study attempted to elucidate the association between DRM-induced autophagy and apoptosis in GBM cells in vitro and in vivo.

\section{Materials and methods}

Cell lines, reagents and antibodies. U87 human GBM cell lines and C6 rat GBM cells were obtained from China Infrastructure of Cell Line Resources, Institute of Basic Medical Sciences, Chinese Academy of Medical Sciences (Beijing, China) and have been authenticated by short tandem repeat (STR) profiling. In addition, STR profiling identified that the original U87 cell line was established in 1968 at the University of Uppsala (RRID: CVCL-GP63). These cells were cultured in DMEM (cat. no. 12100-046; Gibco; Thermo Fisher Scientific, Inc.) supplemented 10\% new-fetal bovine serum (cat.no. 23022-8615; Zhejiang Tianhang Biotechnology Co., Ltd.) and $100 \mathrm{U} / \mathrm{ml}$ penicillin/streptomycin (cat. no. C0222; Beyotime Institute of Biotechnology). The cells were placed in an incubator at $37^{\circ} \mathrm{C}$ with $5 \% \mathrm{CO}_{2}$. DRM was purchased from Sigma-Aldrich; Merck KGaA. DMSO (cat. no. D2650) and chloroquine (CQ; cat. no. C6628) were purchased from Merck KGaA. The antibodies used were as follows: Autophagy-related 5 (Atg5; dilution, 1:1,000; cat. no. 12994; Cell Signaling Technology, Inc.), LC3 (detects both LC3I and LC3II; dilution, 1:1,000; cat. no. 4599; Cell Signaling Technology, Inc.), p62 (dilution, 1:1,000; cat. no. 23214; Cell Signaling Technology, Inc.), Ki-67 (dilution, 1:1,000; cat. no. 9027; Cell Signaling Technology, Inc.) and $\beta$-actin (dilution, 1:1,000; cat. no. 4970; Cell Signaling Technology, Inc.). The Goat Anti-Rabbit IgG secondary antibody was obtained from OriGene Technologies, Inc. (dilution, 1: 2,000; cat. no. TA130015). All antibodies were dissolved antibody dilution buffer (cat. no. A1800; Beijing Solarbio Science \& Technology Co., Ltd.). GFP-LC3 plasmid and GFP plasmid were obtained from BioVector NTCC, Inc.
Transmission electron microscopy (TEM). The cells were incubated with or without DRM for $48 \mathrm{~h}$. The culture medium was discarded, and the cells were washed three times with PBS. They were then fixed overnight with $2.5 \%$ glutaraldehyde at $4^{\circ} \mathrm{C}$ and subsequently fixed with $1 \%$ osmium tetroxide for $1-2 \mathrm{~h}$ at $4^{\circ} \mathrm{C}$. Next, the cells were dehydrated using a graded series of ethanol solutions (30, 50, 70, 90 and 100\%) for $10 \mathrm{~min}$ at a time, and embedded in Epoxy Embedding medium (Merck KGaA) and polymerized at $37^{\circ} \mathrm{C}$ for $24 \mathrm{~h}$. Finally, it was dyed with $3 \%$ uranium acetate and lead citrate for $30 \mathrm{~min}$ at room temperature. The ultrathin sections $(0.1 \mu \mathrm{m})$ were observed using a transmission electron microscope (H7650; Hitachi, Ltd.). Treatment without DRM was used as a control.

Plasmid transfection. The cells were cultured in 6-well plates at a density of $2 \times 10^{5}$ cells/well for $24 \mathrm{~h}$. The cells were transfected with green fluorescent protein $3 \mu \mathrm{g}$ GFP-LC3 $(2.5 \mu \mathrm{g} / \mu \mathrm{l})$ plasmid and $3 \mu \mathrm{g}$ empty plasmid $(4.8 \mu \mathrm{g} / \mu \mathrm{l})$ containing no LC3 protein using Lipofectamine ${ }^{\circledR} 2000$ (cat. no. 11668019; Invitrogen; Thermo Fisher Scientific, Inc.) according to the manufacturer's instructions. Subsequently, transfected cells were incubated in serum-free medium at $37^{\circ} \mathrm{C}$ for $4 \mathrm{~h}$. After $4 \mathrm{~h}$, the transfected cells were incubated with fresh medium or fresh medium containing DRM for $48 \mathrm{~h}$. After $48 \mathrm{~h}$, the DRM-treated transfected cells were then visualized under an inverted fluorescence microscope (Olympus Corporation). Furthermore, at $48 \mathrm{~h}$ after transfection, transfected cells without DRM treatment were harvested using RIPA lysis buffers (cat. no. P0013B; Beyotime Institute of Biotechnology) supplemented with protease inhibitors (cat. no. ST506; Beyotime Institute of Biotechnology). Next, total proteins were used for western blot analysis. DRM-treated transfected cells were not harvested. Treatment without DRM or empty plasmid were used as a control.

Western blot analysis. U87 and C6 cells were incubated with various concentrations of $\operatorname{DRM}(0,5,10$ and $15 \mu \mathrm{M})$ at $37^{\circ} \mathrm{C}$ for $48 \mathrm{~h}$. Tumor tissue was ground to powder in a mortar containing liquid nitrogen. The DRM-treated cells and tumor tissue powder were harvested in RIPA lysis buffers (cat. no. P0013B; Beyotime Institute of Biotechnology) supplemented with protease inhibitors (cat. no. ST506; Beyotime Institute of Biotechnology). Next, the concentration of total proteins was determined using a BCA assay kit (cat. no. P0012; Beyotime Institute of Biotechnology). Total proteins (30 $\mu \mathrm{g}$ protein/lane) were separated by $12 \%$ sodium dodecyl sulphate-polyacrylamide gel electrophoresis and transferred to polyvinylidene fluoride membranes (Millipore Sigma; Merck KGaA). The membranes were then blocked with 5\% fat-free milk in TBS-0.1\% Tween 20 buffer for $2 \mathrm{~h}$ at $37^{\circ} \mathrm{C}$. Next, the blots were incubated with primary antibodies overnight at $4^{\circ} \mathrm{C}$. Subsequently, the protein bands were probed with HRP-conjugated goat anti-rabbit IgG secondary antibody (dilution, 1:2,000; cat. no. TA130015) for $1.5 \mathrm{~h}$ at room temperature. Then, each band was visualized using BeyoECL Moon (cat. no. P0018 FM; Beyotime Institute of Biotechnology). Finally, the protein bands were analyzed using Image $\mathrm{Lab}^{\mathrm{TM}}$ Software (version 5.2.1; Bio-Rad Laboratories, Inc.) on a ChemiDoc XRS+(Bio-Rad Laboratories, Inc.). 


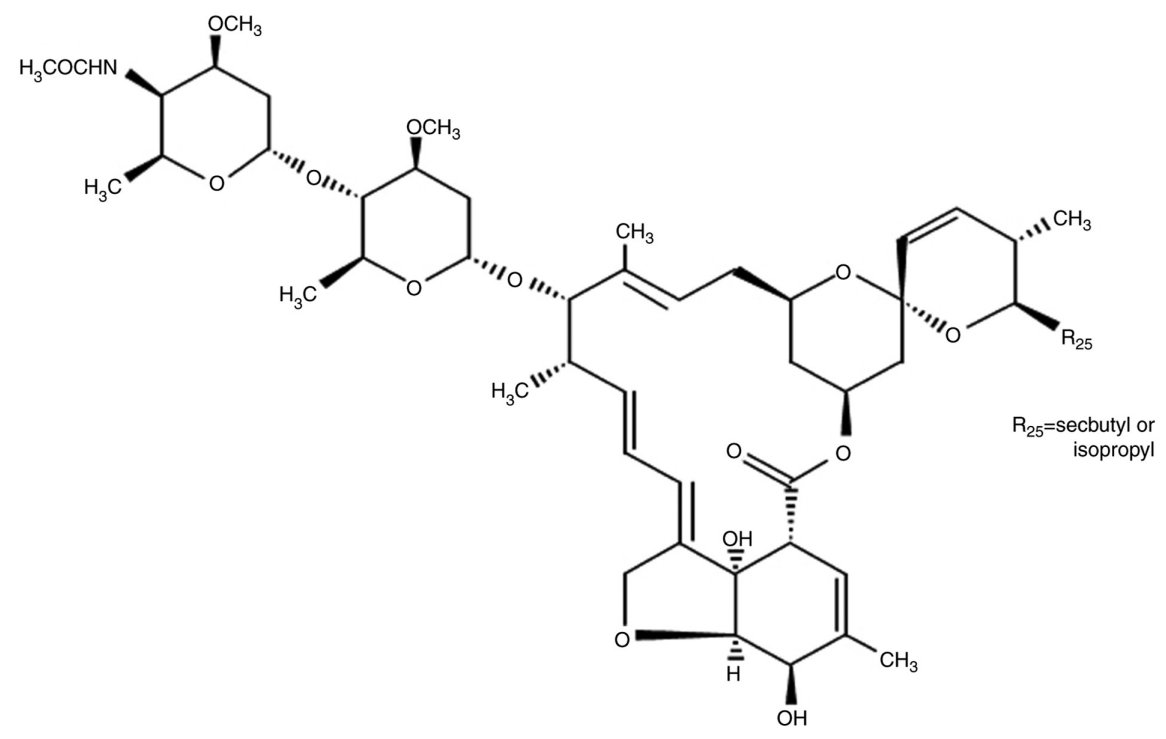

Figure 1. Structure of doramectin.

Analysis of autophagy with $C Q$. The autophagy inhibitor CQ was also used to block autophagy at a final concentration of $15 \mu \mathrm{M}$. Briefly, U87 and C6 cells $\left(1 \times 10^{5}\right.$ cells/well) in a 6-well plate were pretreated with CQ $(15 \mu \mathrm{M})$ at $37^{\circ} \mathrm{C}$ for $2 \mathrm{~h}$, and then cells were treated with DRM $(15 \mu \mathrm{M})$ at $37^{\circ} \mathrm{C}$ for $48 \mathrm{~h}$. Cells were collected for MTT, colony formation, western blotting, DAPI staining and Annexin V-FITC/PI staining analysis.

MTT assay. U87 and C6 cells were seeded into 96-well plates at a density of $3 \times 10^{3}$ cells/well and incubated overnight at $37^{\circ} \mathrm{C}$ for $24 \mathrm{~h}$. DMEM supplemented with DRM alone or together with the autophagy inhibitor CQ was added to the 96-well plates for $48 \mathrm{~h}$. MTT $(1 \mathrm{mg} / \mathrm{ml}$ dissolved in PBS; $100 \mu \mathrm{l} /$ well; cat. no. M2128; Merck KGaA) was then added to each well and cells were incubated for an additional $4 \mathrm{~h}$ at $37^{\circ} \mathrm{C}$. MTT was carefully removed and $150 \mu$ DMSO was added. Absorbance was measured on a microplate reader (BioTek Instruments, Inc.) at a wave length of $450 \mathrm{~nm}$. The cell viability inhibition rate (IR) was calculated as the ratio between the OD of the CQ, CQ+DRM and DRM group and the OD of the control group. Cells in the control group were not treated with DRM and CQ.

Colony formation assay. U87 and C6 cells were seeded into 6 -well plates at a density of $3 \times 10^{2}$ cells/well. Following overnight incubation at $37^{\circ} \mathrm{C}, \mathrm{U} 87$ and C6 cells were treated with DRM $(15 \mu \mathrm{M})$ alone or together with the autophagy inhibitor CQ $(15 \mu \mathrm{M})$ at $37^{\circ} \mathrm{C}$ for $48 \mathrm{~h}$. The culture medium was discarded, and the cells were washed with PBS three times. The cells were then incubated with fresh medium at $37^{\circ} \mathrm{C}$. After 2 weeks, the colonies were fixed with $4 \%$ formaldehyde for $30 \mathrm{~min}$ at room temperature and stained with $0.4 \%$ crystal violet for $10 \mathrm{~min}$ at room temperature. Subsequently, the counts of cell colonies were manually scored. The number of colonies was counted and quantified. Colony formation quantification was performed using ImageJ software (version 2.0; National Institutes of Health). A colony was defined as $>50$ cells. Cells in the control group were not treated with DRM and CQ.
DAPI staining. The cells were seeded into 6-well plates at a density of $3 \times 10^{2}$ cells/well and treated with $15 \mu \mathrm{M}$ DRM alone or together with an autophagy inhibitor $(\mathrm{CQ}, 15 \mu \mathrm{M})$ for $48 \mathrm{~h}$ at $37^{\circ} \mathrm{C}$. The cells were harvested, washed twice with PBS, fixed with $4 \%$ formaldehyde for $10 \mathrm{~min}$ at room temperature and stained with DAPI (cat. no. D8471; Merck KGaA) staining solution according to the manufacturer's instructions for $10 \mathrm{~min}$ at $37^{\circ} \mathrm{C}$. The images were immediately captured using a fluorescence microscope (Olympus Corporation). Images were analyzed using Image Pro Plus v. 5.1 software (Media Cybernetics, Inc.). Cells in the control group were not treated with DRM and CQ.

Annexin V-FITC/PI staining for cell apoptosis. An Annexin V-FITC/PI apoptosis detection kit (cat. no. C1062S; Beyotime Institute of Biotechnology) was used to distinguish apoptotic cells from normal cells. U87 and C6 cells were incubated with DRM alone or together with the autophagy inhibitor CQ for $48 \mathrm{~h}$. Cells were harvested and stained with the FITC-labeled Annexin V and PI for $15 \mathrm{~min}$ in the dark. Flow cytometry was conducted immediately to detect apoptotic cell populations. A BD Biosciences FACS Calibur flow cytometer (BD Biosciences) was immediately used to detect apoptotic cell populationsand data were analyzed using Flow Jo 7.6.2 (Tree Star, Inc.).

RNA isolation. The total RNA of each sample was extracted using a High Pure RNA Isolation Kit (cat. no. 1828665; Roche Diagnostics) according to the manufacturer's instructions. The total RNA of triplicate samples treated with or without DRM $(15 \mu \mathrm{M})$ for $48 \mathrm{~h}$ at $37^{\circ} \mathrm{C}$ was then sent to Wuhan Boyue Zhihe Biotechnology Co., Ltd. RNA samples were then digested with RNase free DNase I (cat. no. 89836; Invitrogen; Thermo Fisher Scientific, Inc.) to eliminate residual genomic DNA, and the digestion products were purified using magnetic beads (Axygen; Corning, Inc.). Then, the quality and integrity of the total RNA were assessed using an Agilent 2100 Bioanalyzer (Agilent Technologies, Inc.) and 1.2\% agarose gel electrophoresis. The RNA concentration was measured using a Nano Drop 
2000 instrument (Nano Drop Technologies; Thermo Fisher Scientific, Inc.). High-quality RNA samples with OD260/280 ratios ranging between 1.8 and 2.2 and OD260/230 $\geq 1.8-2.2$, RNA integrity number (RIN) $\geq 7$ and total RNA concentration $\geq 50 \mathrm{ng} / \mu \mathrm{l}$ were used for library preparation. After the RNA sample passed the test, the eukaryotic mRNA (in the case of prokaryote, the mRNA was enriched by removing rRNA through the kit) was enriched using magnetic beads with oligo (DT). RNA sequencing libraries were generated using the KAPA stranded RNA-Seq Kit with RiboErase (HMR; cat. no. KK8483; Kapa Biosystems; Roche Diagnostics) with multiplexing primers according to the manufacturer's protocol. Subsequently, a fragment buffer was added to break the mRNA into short segments. mRNA was used as a template to synthesize a single-stranded cDNA with six base random primers. Then, buffer, dNTPs, DNA polymer I and RNase H were added to synthesize double-stranded cDNA. Then, the double-stranded cDNA was purified with AMPure XP beads. The purified double-stranded cDNA was first repaired with A-tail and connected with the sequencing connector; then, the fragment size was selected using AMPure XP beads. Subsequently, the second strand of U-containing cDNA was degraded with user enzyme so that the final sequencing information came from the first strand of cDNA, thus preserving the strand orientation of mRNA. Finally, the PCR amplification was carried out, and the PCR products were purified with AMPure XP beads to obtain the chain-specific cDNA library. After the construction of the library, qubit 3.0 fluorometer (cat. no. Q33216; Thermo Fisher Scientific, Inc.) was used for preliminary quantification, and the library was diluted to 1 $\mathrm{ng} / \mu \mathrm{l}$. Then, Qsep100 was used to detect the insert size of the library. After the insert size met the expectation, qPCR was used to accurately quantify the effective concentration of the library (the effective concentration of the library was $>2 \mathrm{nM}$ ), so as to ensure the quality of the library. After the library passed the inspection, different libraries were pooled according to the requirements of effective concentration and target off line data volume, following which HiSeq sequencing was carried out. Paired end sequencing was performed using an Illumina Hiseq X Ten with a read length of $150 \mathrm{bp}$. A total of $1 \mu \mathrm{g}$ total RNA was used for each Illumina library preparation. FastQC v0.11.9 software (Babraham Bioinformatics; https://www. bioinformatics.babraham.ac.uk/projects/fastqc/) was used for quality analysis of the sequencing data in this project. The number of reads per gene was calculated using featureCounts V1.6.0 (featureCounts is a tool in the Subread v2.0.1 package; http://subread.sourceforge.net).

Data processing and functional annotation. Gene expression was standardized by fragments per kilobase per million mapped fragments using featureCounts v1.5.0. (36). The following analyses were conducted on differentially expressed genes (DEGs): i) A Venn diagram was drawn to identify common and unique DEGs between the groups using Venny 2.1.1 (https://bioinfogp.cnb.csic.es/tools/venny/) and a Volcano plot generated by ggplot2 v.3.0.0 (37) in R Package 3.5.3 (https://neuroconductor.org/neurocLite.R) was used to analyze the screening of differentially expressed genes between samples; ii) Genesis 1.8.1 (38) was used for hierarchical clustering, it was used to compare the expression of DEGs in DRM vs. control groups using cluster analysis software; and iii) Gene Ontology (GO; http://www.geneontology.org) and Kyoto Encyclopedia of Genes and Genomes (KEGG; http://www.genome.jp/), pathway annotation and enrichment analyses were carried out using the cluster profiler package 3.10 .1 (https://bioconductor. org/packages/clusterProfiler/) in R Package 3.5.3 (https://neuroconductor.org/neurocLite.R) (39). Pathview in KEGG was used to analyze data (https://www.kegg.jp/pathway/map04140 and https://www.kegg.jp/kegg/mapper/color.html).

Animal models. All animal experiments were carried out at Harbin Weike Biotechnology Co., Ltd. The housing conditions were as follows: $24^{\circ} \mathrm{C}, 50-60 \%$ humidity and $12: 12 \mathrm{~h}$ light-dark cycle. Animals were given free access to commercial rat pellet diet and tap water. A total of 36 female BALB/c mice were obtained from Beijing Vital River Laboratory Animal Technology Co., Ltd. Each BALB/c mice weighed about $17 \pm 1.58 \mathrm{~g}$ and was 6 weeks old. After 1 week of feeding in a sterile environment, $100 \mu 1$ PBS containing $2.0 \times 10^{6} \mathrm{C} 6$ cells were injected subcutaneously into the flanks of nude mice. After 10 days, tumor-bearing mice were allocated to four groups and treated with either saline $(100 \mu \mathrm{l}$; control group), CQ (20 mg/kg/day CQ in $100 \mu \mathrm{l}$; CQ group), DRM $(14 \mathrm{mg} / \mathrm{kg} /$ day DRM in $100 \mu \mathrm{l}$; DRM group) or DRM+CQ (20 mg/kg/day CQ combined with $14 \mathrm{mg} / \mathrm{kg} / \mathrm{day}$ DRM in $100 \mu \mathrm{l}$; DRM+CQ group) for 24 days. The four treatments were injected intraperitoneally into mice daily. Health and behavior of all nude mice were monitored on a daily basis. The length (L) and width $(\mathrm{W})$ of tumors were measured and calculated every 3 days $\left(\mathrm{V}=1 / 2 \times \mathrm{L} \mathrm{x} \mathrm{W}^{2}\right)$. After 24 days, the tumor volume of mice in the control group made it difficult to live, including difficulty drinking, eating and moving, which brought discomfort to the life of mice. At the same time, the tumor volume had reached the purpose of the present study. First, all mice were humanely euthanized by intraperitoneal injection of Nembutal $(150 \mathrm{mg} / \mathrm{kg})$. Then, death was confirmed using cervical dislocation as a secondary method of euthanasia. All mice showed no vital signs and tumors were extracted for immunostaining and weighing. The maximum tumor volume in the present study was $760 \mathrm{~mm}^{3}$. The experiment progressed 42 days from the injection of mice to euthanasia of mice. There were no mice that died accidentally during the experiment, and the mice showed healthy vital signs.

Immunohistochemical staining. All specimens were fixed in $10 \%$ neutral-buffered formalin for $48 \mathrm{~h}$ at room temperature and embedded in paraffin. Next, $5-\mu \mathrm{m}$-thick sections were dewaxed and rehydrated. All specimens were dewaxed in xylene and rehydrated in a graded series of ethanol solution at room temperature for $5 \mathrm{~min}$ at a time. Sections were treated with $0.01 \mathrm{~mol} / \mathrm{l}$ boiling sodium citrate buffer for 10 min. Subsequently, sections were treated with $3 \% \mathrm{H}_{2} \mathrm{O}_{2}$ at room temperature for $30 \mathrm{~min}$. Next, they were incubated in QuickBlock ${ }^{\mathrm{TM}}$ Blocking Buffer (cat. no. P0260; Beyotime Institute of Biotechnology) at $37^{\circ} \mathrm{C}$ for $20 \mathrm{~min}$. Then, they were incubated in LC3 (dilution, 1:6,000; cat. no. 4599; Cell Signaling Technology, Inc.), p62 (dilution, 1:250; cat. no. 23214; Cell Signaling Technology, Inc.) and Ki-67 (dilution, 1:800; cat. no. 9027; Cell Signaling Technology, Inc.) primary antibodies for $90 \mathrm{~min}$ at $37^{\circ} \mathrm{C}$. With an HRP-conjugated goat 
anti-rabbit IgG (dilution, 1:1,000; cat. no. 40295G; BIOSS) at $37^{\circ} \mathrm{C}$ for $90 \mathrm{~min}$. The sections were incubated with a DAB Horseradish Peroxidase Color Development Kit (cat.no. P0202; Beyotime Institute of Biotechnology) at room temperature for $30 \mathrm{~min}$, and then washed with distilled water two times. Finally, the sections were counter stained with hematoxylin for $10 \mathrm{~min}$ at room temperature and the slides were observed under a light microscope (D5100; Nikon Corporation) and analyzed using ImageJ software (version 2.0; National Institutes of Health). The number of positive cell nuclei in 30 random fields from randomly chosen tumor sections for each animal was counted at a magnification of $x 400$.

TUNEL assay. Cell apoptosis was assessed in vivo using a TUNEL assay. An In Situ Cell Death Detection kit (cat. no. 11684817910; Roche Diagnostics GmbH) was used according to the manufacturer's instructions. All specimens were fixed in $10 \%$ neutral-buffered formalin for $48 \mathrm{~h}$ at room temperature and embedded in paraffin. Sections were first dewaxed in xylene and rehydrated in ethanol solution, after incubation with proteinase $\mathrm{K}$ working solution $(20 \mu \mathrm{M})$ for $30 \mathrm{~min}$ at room temperature. The tumor sections were washed with PBS twice. The slides were exposed to TUNEL reaction mixture prepared freshly for $1 \mathrm{~h}$ at $37^{\circ} \mathrm{C}$ in the dark. Then, the slide were rinsed three times with PBS. All slides were analyzed in a drop of PBS under a fluorescence microscope (Olympus Corporation) and analyzed using ImageJ software (version 2.0; National Institutes of Health). The number of positive cell nuclei in 30 random fields from randomly selected tumor sections for each animal was counted at a magnification of $x 400$.

Statistical analysis. For quantification, Ki-67, Atg5, p62 and LC3 staining intensity was measured from the number of positive cell nuclei in 25\% fields using Image J software (version 2.0; National Institutes of Health). All areas were chosen randomly from all sections. The intensity of bands in western blotting was also measured by ImageJ software (National Institutes of Health). All data are presented as the mean \pm SD of at least three independent experiments. The acquired experimental data were analyzed using SPSS 17.0 software (SPSS, Inc.) and GraphPad Prism 5.0 (GraphPad Software, Inc). The differences between two groups were analyzed using an unpaired Student's t-test. Student's t-test was used when two groups were compared and one-way ANOVA was used when several groups were compared. The Tukey method was used as the post hoc test. $\mathrm{P}<0.05$ was considered to indicate a statistically significant difference.

\section{Results}

DRM increases autophagy in GBM cells. Various methods were used to determine the effect of DRM on the levels of autophagy in GBM cells. TEM results revealed accumulation of autolysosomes and autophagosomes in the DRM group, but not in the control group (Fig. 2A). Furthermore, LC3 puncta were observed using the GFP-LC3 transient transfection assay. Microscopy images indicated that DRM increased the distribution and number of LC3 puncta (Fig. 2B). Additionally, LC3I/LC3II protein expression after transfection was detected by western blotting. The results demonstrated that LC3I/LC3II protein expression increased after transfection without DRM treatment (Fig. 2C). LC3 is a marker of autophagy. During the initiation of autophagy, LC3I enzymatically decomposes a small polypeptide segment and transforms it into LC3II (40). The ratio of LC3II/LC3I can be used to estimate the level of autophagy (41). At the same time, p62 and Atg5 proteins are important indicators of regulation of LC3I and LC3II protein conversion $(42,43)$. Western blot analysis demonstrated that DRM induced the accumulation of LC3I/LC3II and Atg5 in U87 and C6 cells when the DRM concentration was $15 \mu \mathrm{M}$. In addition, DRM $(15 \mu \mathrm{M})$ induced degradation of p62 in U87 and C6 cells (Fig. 2D-G). In combination, these data suggested that DRM could promote autophagy initiation in GBM cells.

DRM-induced autophagy decreases proliferation in GBM cells. The effect of DRM-induced autophagy on GBM cells was further explored. Western blot analysis was conducted to detect the protein expression levels of p62 and LC3I/LC3II in the presence of the autophagy inhibitor CQ. As expected, the autophagy inhibitor CQ partially inhibited DRM-induced cell autophagy (Fig. 3A-C). In the DRM+CQ group compared with the DRM group, the LC3I/LC3II protein expression was decreased. Subsequently, MTT and colony formation assays were used to assess the viability and colony formation ratio of GBM cells. According to MTT assay results, DRM significantly reduced cell viability compared with DRM combined with CQ in U87 and C6 cells (Fig. 3F). As shown in Fig. 3D and $\mathrm{E}$, treatment with DRM combined with CQ was associated with a significant increase in the colony formation ability of U87 and C6 cells compared with treatment with DRM only. In conclusion, these results indicated that DRM-induced autophagy could reduce the proliferation of GBM cells.

Inhibition of autophagy decreases DRM-induced apoptosis. The effect of DRM-induced autophagy on GBM cell apoptosis was further investigated. First, DAPI staining was performed to explore the role of autophagy in DRM-induced DNA double-strand breaks. In Fig. 4A, the fragmented DNA was increased in the DRM only group compared with the DRM+CQ group. Subsequently, apoptosis was analyzed by flow cytometry. Apoptosis was increased in the DRM group compared with the DRM+CQ, CQ and control groups (Fig. 4B and C). These findings suggested that DRM-induced autophagy could promote apoptosis in GBM cells.

Analysis of DEGs in DRM-treated C6 cells. Comparison of DRM-treated C6 cells with untreated C6 cells revealed a higher degree of differential expression of genes. First, to ensure the reliability of the sequencing results, the inter-sample correlation was analyzed (Fig. 5A). As shown by the Venn diagram and Volcano plot in Fig. 5B and C, the transcript expression profiles identified 3,747 DEGs, including 1,660 upregulated and 2,087 downregulated genes.

GO enrichment analysis of DEGs. To further explore the potential functions of DEGs, the DEGs in the treatment groups were examined by GO functional enrichment analysis in relation to the control group. Each group of DEGs 
A

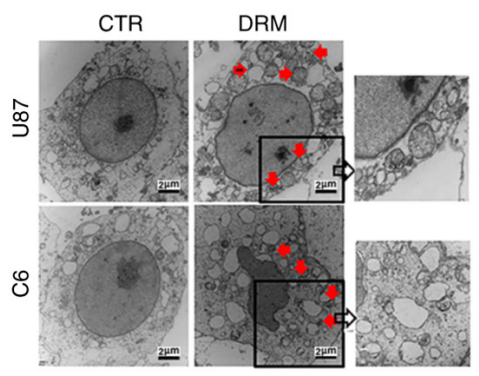

D

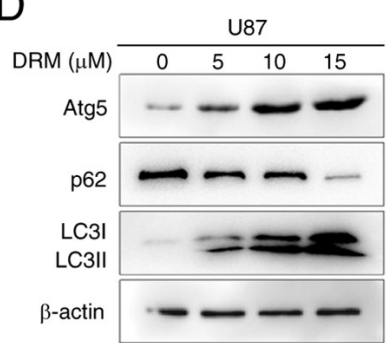

B

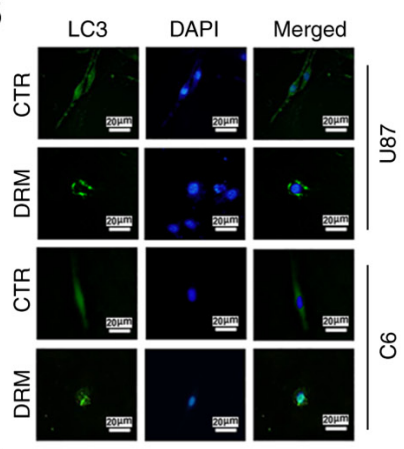

E

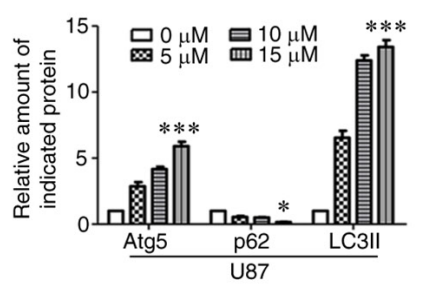

C
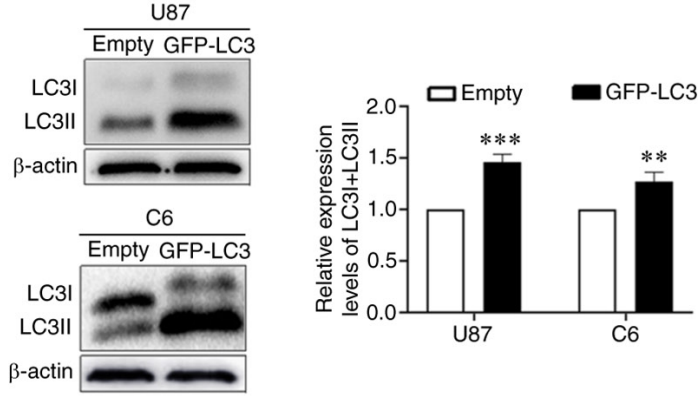

G
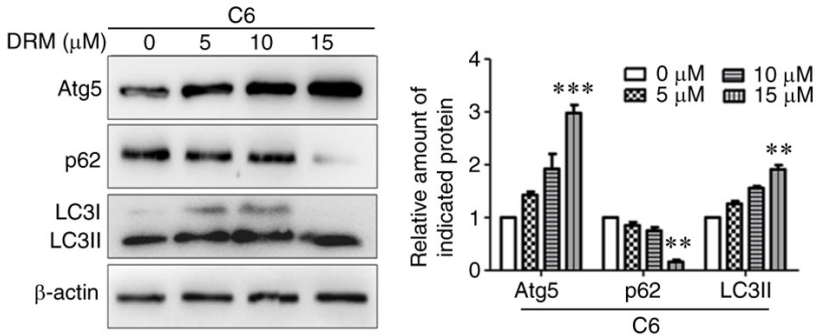

Figure 2. DRM-induced autophagy in U87 and C6 cells. (A) Transmission electron microscopy revealed autophagosome accumulation in U87 and C6 cells treated with 0 or $15 \mu \mathrm{M}$ DRM for $48 \mathrm{~h}$. Red arrows indicate autophagosomes. Scale bar, $2 \mu \mathrm{m}$. (B) Fluorescence microscopy using GFP-LC3 as a measure of the autophagic response in U87 and C6 cells treated with 0 or $15 \mu \mathrm{M}$ DRM for $48 \mathrm{~h}$. Scale bar, $20 \mu \mathrm{m}$. (C) U87 and C6 cells were transfected with the GFP-LC3 plasmid and empty plasmid, and LC3I/LC3II and $\beta$-actin protein expression was examined by western blot, and semi-quantitative analysis of the protein expression levels of LC3I/LC3II and $\beta$-actin indifferent groups was performed. (D) U87 cells were treated with different concentrations of DRM $(0,5,10$ and $15 \mu \mathrm{M})$ for $48 \mathrm{~h}$. Western blot analysis was performed to detect protein expression levels of Atg5, p62, LC3I/LC3II and $\beta$-actin. (E) Graphical representation of semi-quantitative analysis of autophagic proteins in U87 cells. (F) Protein expression level of Atg5, p62, LC3I/LC3II and $\beta$-actin in C6 cells treated with different concentrations of DRM $(0,5,10$ and $15 \mu \mathrm{M})$ for $48 \mathrm{~h}$, as determined by western blot. (G) Graphical representation of semi-quantitative analysis of autophagic proteins in $\mathrm{C} 6$ cells. The results are presented as the mean $\pm \mathrm{SD}, \mathrm{n} \geq 3$. ${ }^{*} \mathrm{P}<0.05,{ }^{* * *} \mathrm{P}<0.01$ and ${ }^{* * * *} \mathrm{P}<0.001$ vs. empty or $0 \mu \mathrm{M}$. Atg5 , autophagy-related 5; CTR, control; DRM, doramectin; GFP, green fluorescent protein.

A

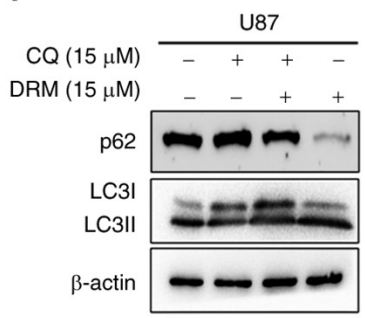

D
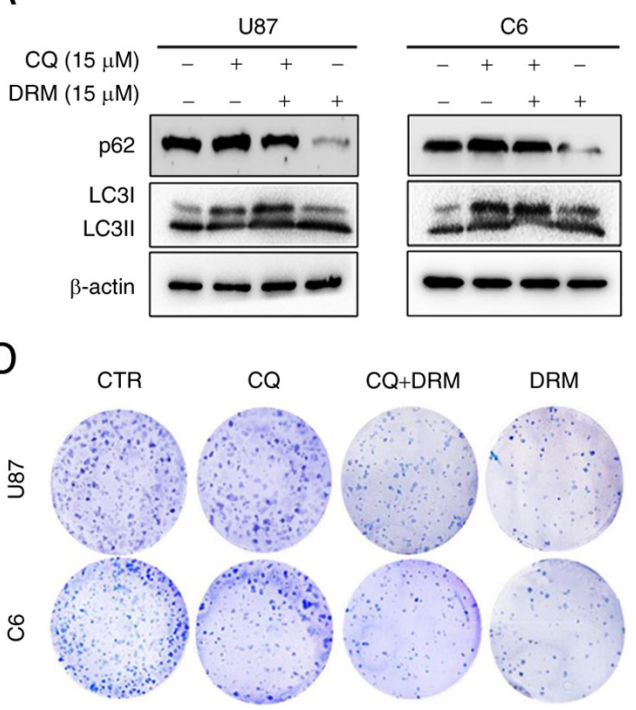

B

$\mathrm{E}$
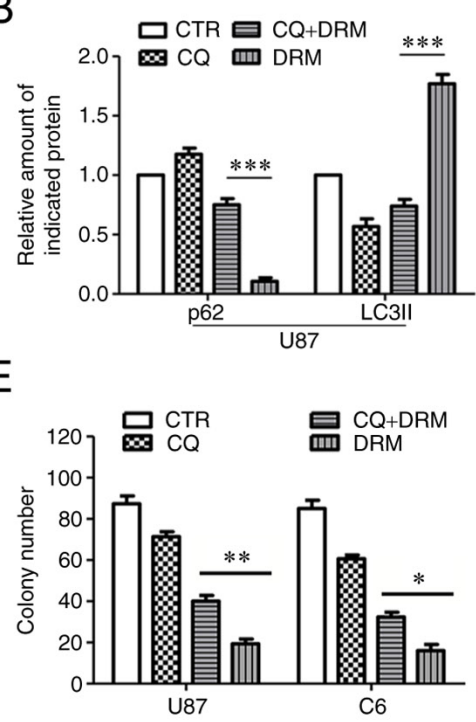

C

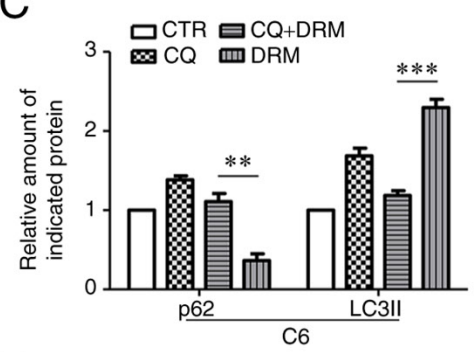

$\mathrm{F}$

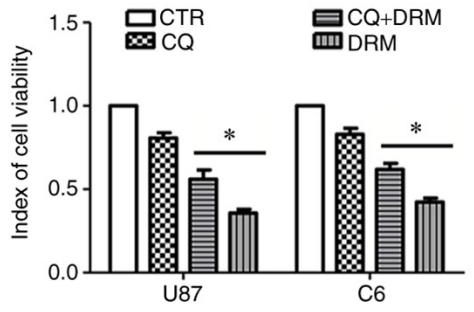

Figure 3. Autophagy inhibitsU87 and C6 cell proliferation. (A) CQ induced autophagic protein changes in U87 and C6 cells. Graphical representation of semi-quantitative analysis of autophagic proteins in (B) U87 and (C) C6 cells. (D) Colony formation assay for U87 and C6 cells treated with or without DRM $(15 \mu \mathrm{M})$ in the absence or presence of CQ $(15 \mu \mathrm{M})$. (E) Quantitative analysis of colony formation. (F) U87 and C6 cells were treated with or without DRM $(15 \mu \mathrm{M})$ in the absence or presence of CQ $(15 \mu \mathrm{M})$ for $48 \mathrm{~h}$. Cell viability was determined using the MTT assay. Results are presented as the mean \pm SD, $\mathrm{n} \geq 3$; ${ }^{*} \mathrm{P}<0.05,{ }^{* *} \mathrm{P}<0.01$ and ${ }^{* * *} \mathrm{P}<0.001$. CQ, chloroquine; CTR, control; DRM, doramectin.

covered three aspects of biology. The top 50 functionally enriched classes in each group are shown in Fig. 6. With regards to biological processes, the DEGs were mainly enriched in 'chromosome segregation', 'nuclear division', 'mitotic nuclear division', 'nuclear chromosome segregation' and 'cell division' (Fig. 6A). With regards to cellular 
A
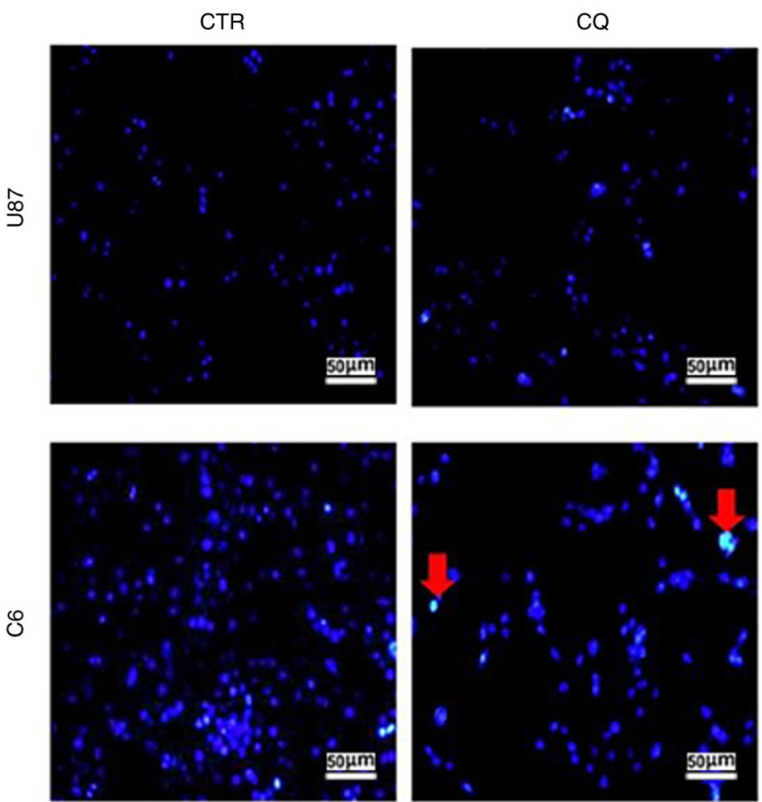

B
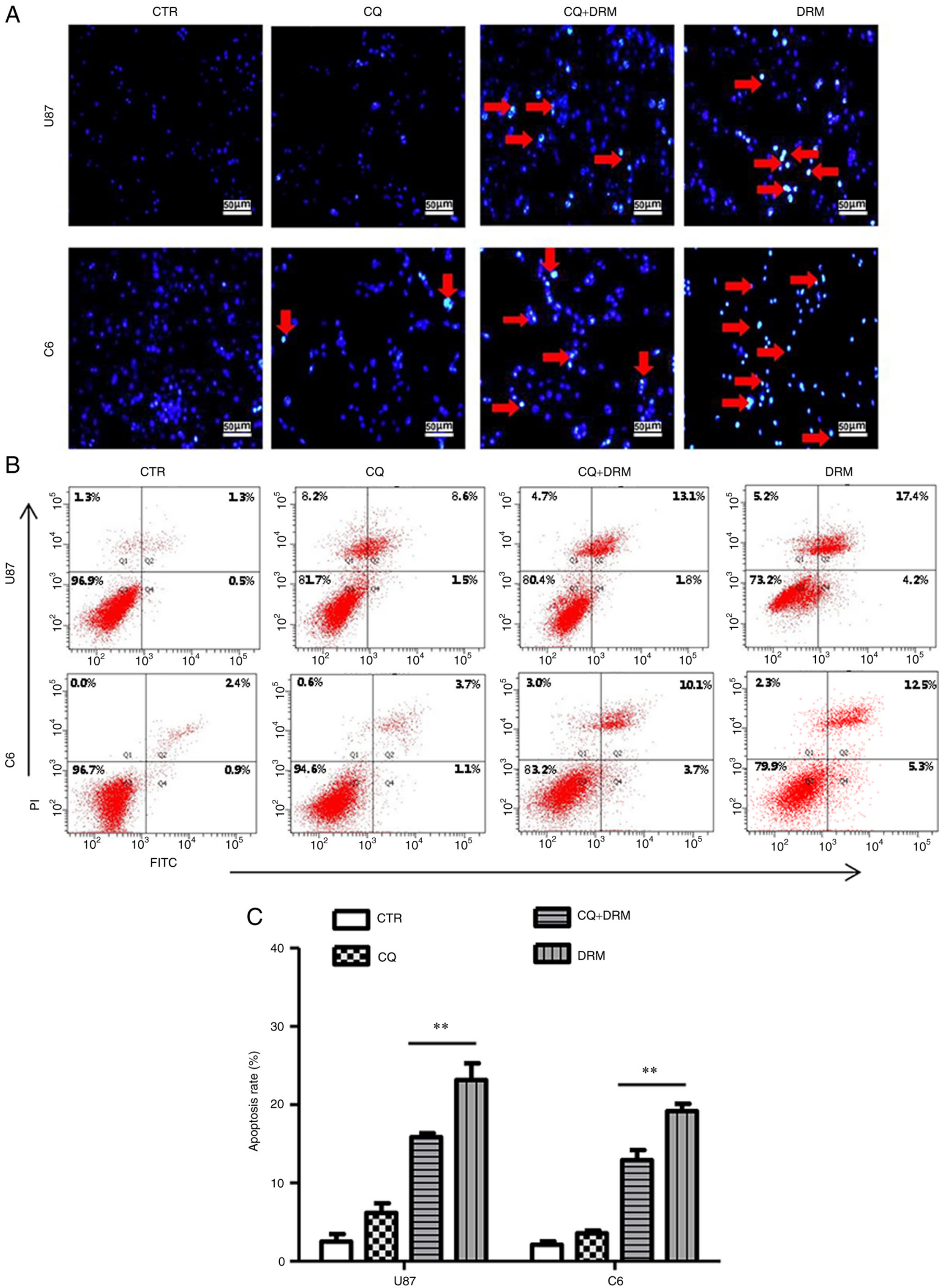

Figure 4. Autophagy promotes the apoptosis of U87 and C6 cells. (A) DAPI staining images of U87 and C6 cells were captured using a fluorescence microscope following treatment with or without DRM $(15 \mu \mathrm{M})$ in the absence or presence of CQ $(15 \mu \mathrm{M})$ for 48h. Scale bar, $50 \mu \mathrm{m}$. (B) U87 and C6 cells were treated with or without DRM $(15 \mu \mathrm{M})$ in the absence or presence of CQ $(15 \mu \mathrm{M})$ for $48 \mathrm{~h}$, and the apoptotic cell ratio was measured by flow cytometry. (C) Graphical representation of quantitative analysis of the apoptotic rate. The results are presented as the mean $\pm \mathrm{SD}$ of at least three independent experiments. ${ }^{* *} \mathrm{P}<0.01$. CQ, chloroquine; CTR, control; DRM, doramectin. 
A

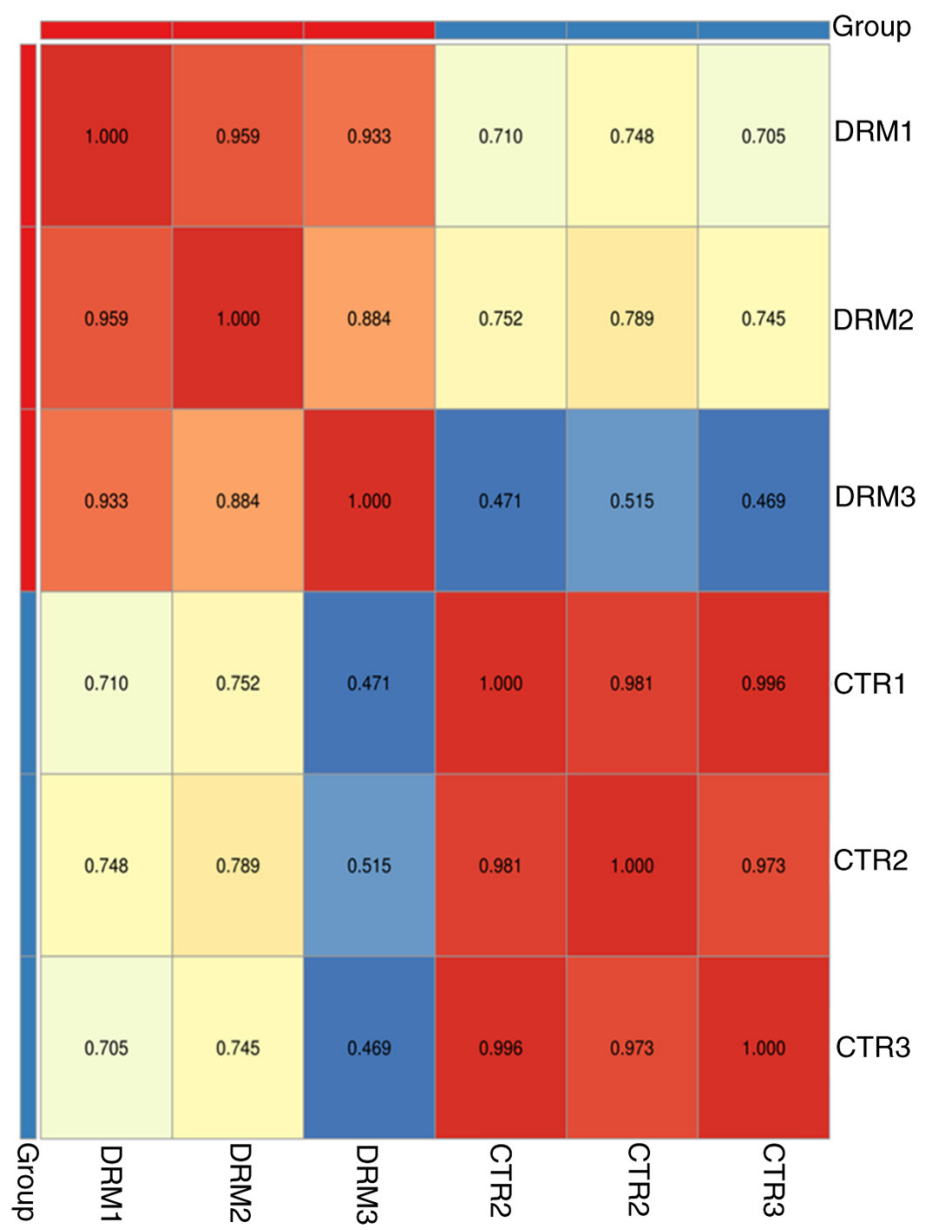

B
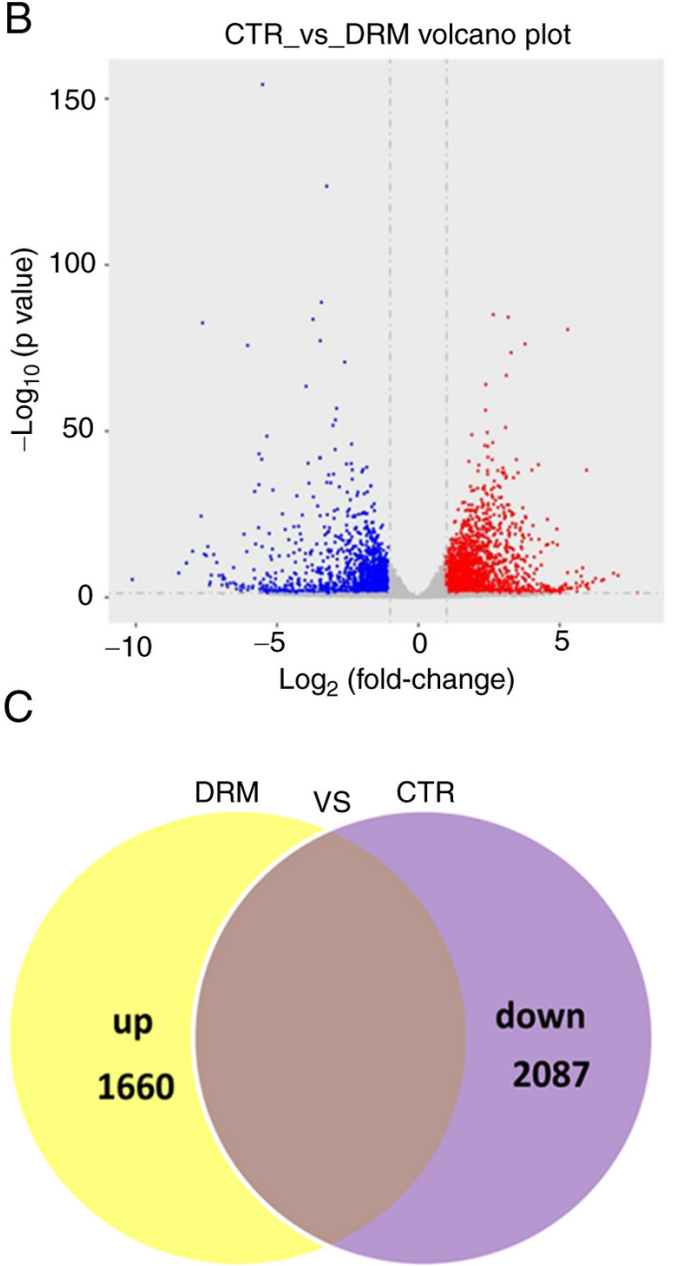

Figure 5. RNA-sequencing of the DRM and control groups. Transcriptome analysis was performed on C6 cells treated with or without DRM (15 $\mu \mathrm{M})$ for $48 \mathrm{~h}$. (A) Correlation analysis among 6 samples. Different colored squares represent the degree of correlation between the two groups. (B) Volcano plot of significant DEGs. Blue dots represent downregulated DEGs, red dots represent upregulated DEGs and gray dots represent non-DEGs. (C) Venn diagram depicting the number of DEGs. CTR, control; DEGs, differentially expressed genes; DRM, doramectin.

components, the DEGs were mainly enriched in 'focal adhesion', 'cell-substrate junction', 'cell-substrate adherens junction', 'cytosolic ribosome' and 'chromosome, centromeric region' (Fig. 6B). With regards to molecular functions, the DEGs were mainly enriched in 'structural constituent of ribosome', 'growth factor binding', 'cell adhesion molecule binding', 'actin binding' and 'integrin binding' (Fig. 6C).

KEGG signaling pathway enrichment analysis of DEGs. In order to further explore the effect of DRM on GBM signaling pathways, KEGG functional enrichment analysis of DEGs was also performed. The results in Fig. 7 revealed that the autophagy signaling pathway was not the only pathway that was enriched. Multiple signaling pathways associated with autophagy and apoptosis, such as 'DNA replication' and the 'p53 signaling pathway', 'mTOR signaling pathway', 'PI3K/Akt signaling pathway' and 'MAPK signaling pathway', were significantly enriched in C6 DRM-treated cells. A number of autophagy-related pathways were changed, indicating that the autophagy pathway was altered in the DRM group compared with the control group and that the DEGs in these pathway categories may be closely associated with DRM-induced autophagy. The top 100 signaling pathways that were altered after DRM treatment of C6 cells were randomly shown.

Analysis of DEGs involved in the autophagy signaling pathway. DEGs involved in autophagy are shown in the heat map in Fig. 8. Following treatment of C6 cells with DRM for 48 h, 51 DEGs were shown. In Fig. 9, a number of the genes that influence and control autophagy were shown, and these were also shown in the heat map, for example, a series of autophagy-related genes (Atgs), mTOR, AKT and pI3K, were identified.

DRM-induced autophagy suppresses C6 cell xenograft growth in vivo. The present study further determined the effect of DRM-induced autophagy on the regulation of GBM xenograft growth in vivo. No obvious differences in the weight of the mice were observed between the DRM, CQ and CQ+DRM groups and the control group (Fig. 10A). When comparing the two DRM intervention groups, significant suppression of tumor growth was observed in the CQ-untreated group compared with the DRM+CQ-treated group (Fig. 10B and C). To further verify that DRM-induced autophagy can inhibit GBM cell proliferation, immunohistochemical analysis of tumor sections was performed. As 
A

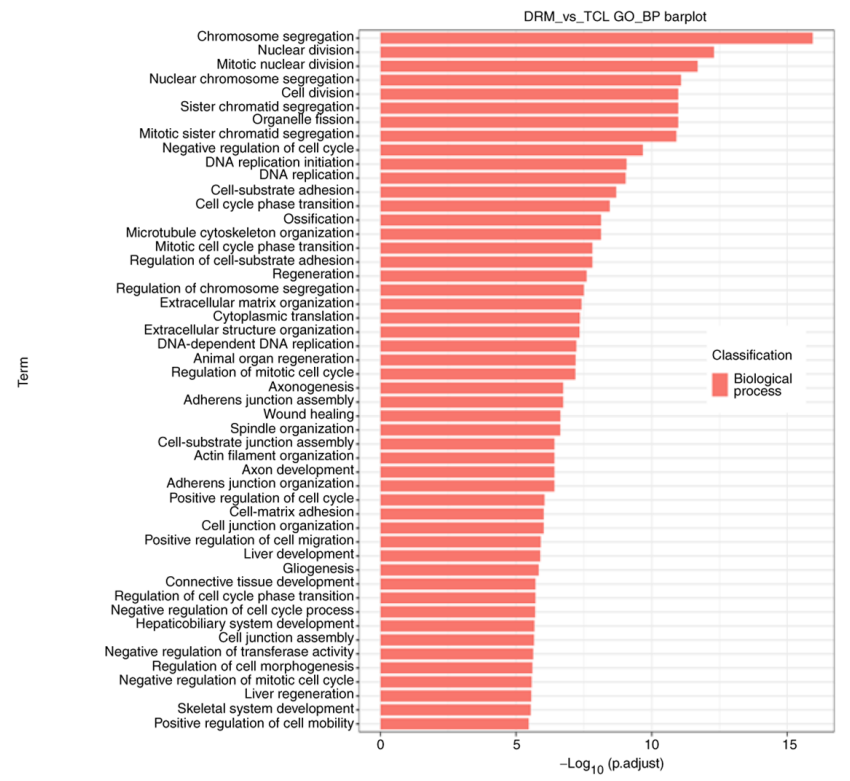

B

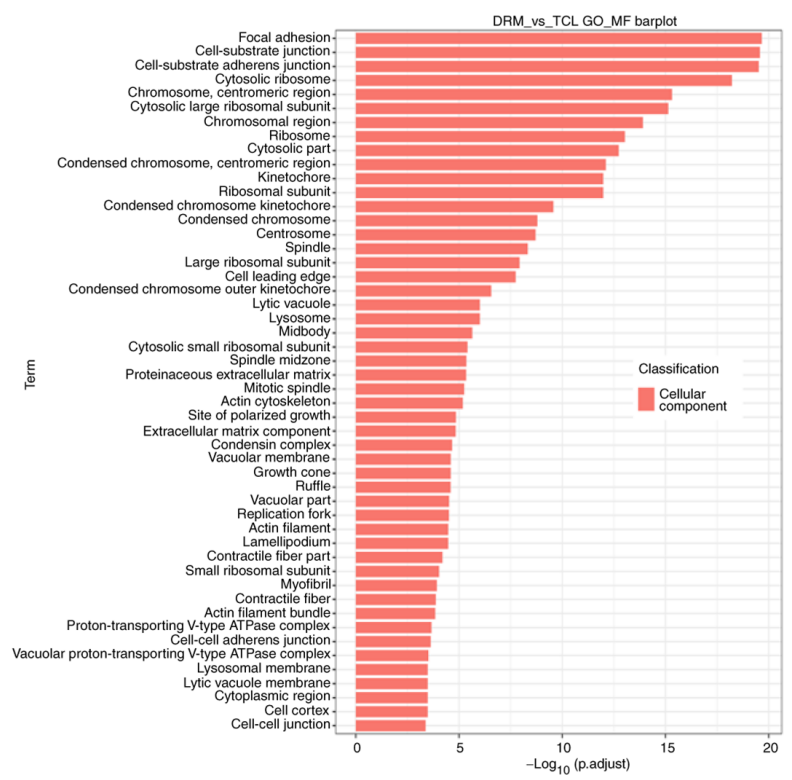

C

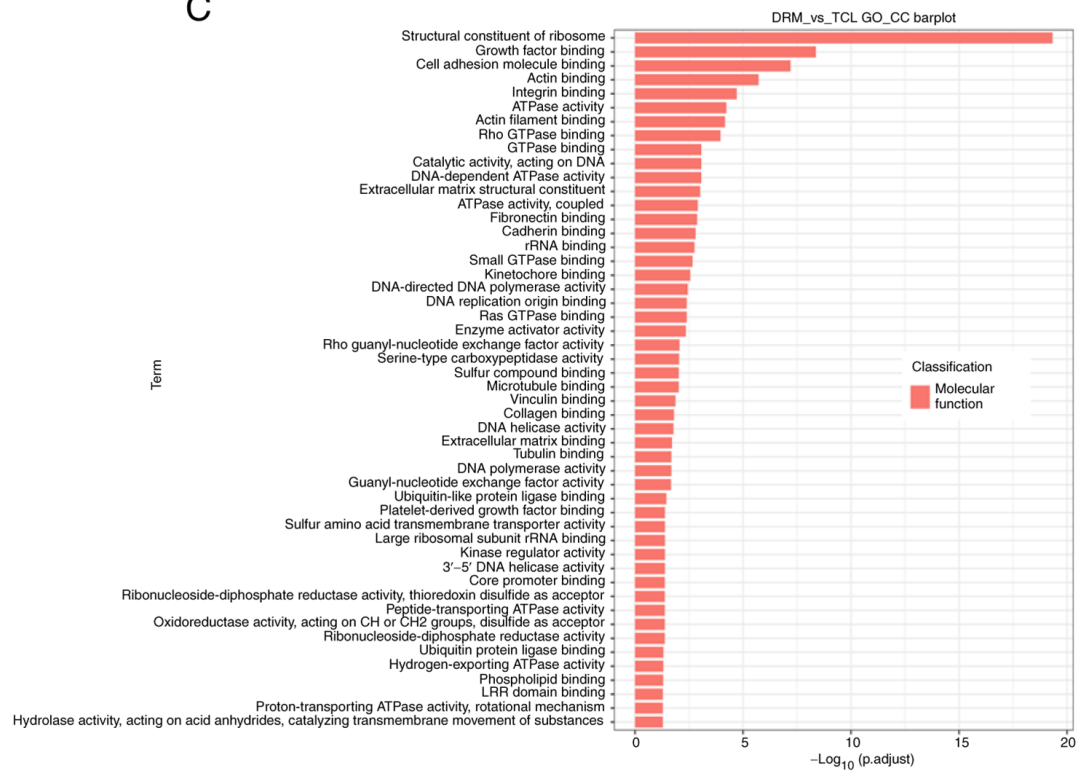

Figure 6. Significantly enriched terms of GO analysis. (A) GO annotation analysis revealed that 50 BPs were altered in DRM-treated C6 cells compared with the control group. (B) GO annotation analysis showed that $50 \mathrm{CCs}$ were altered in DRM-treated C6 cells compared with the control group. (C) GO annotation analysis showed that $50 \mathrm{MFs}$ were altered in DRM-treated C6 cells compared with the control group. BP, biological processes; CC, cell components; CTR, control; DRM, doramectin; GO, Gene Ontology; MF, molecular function. 

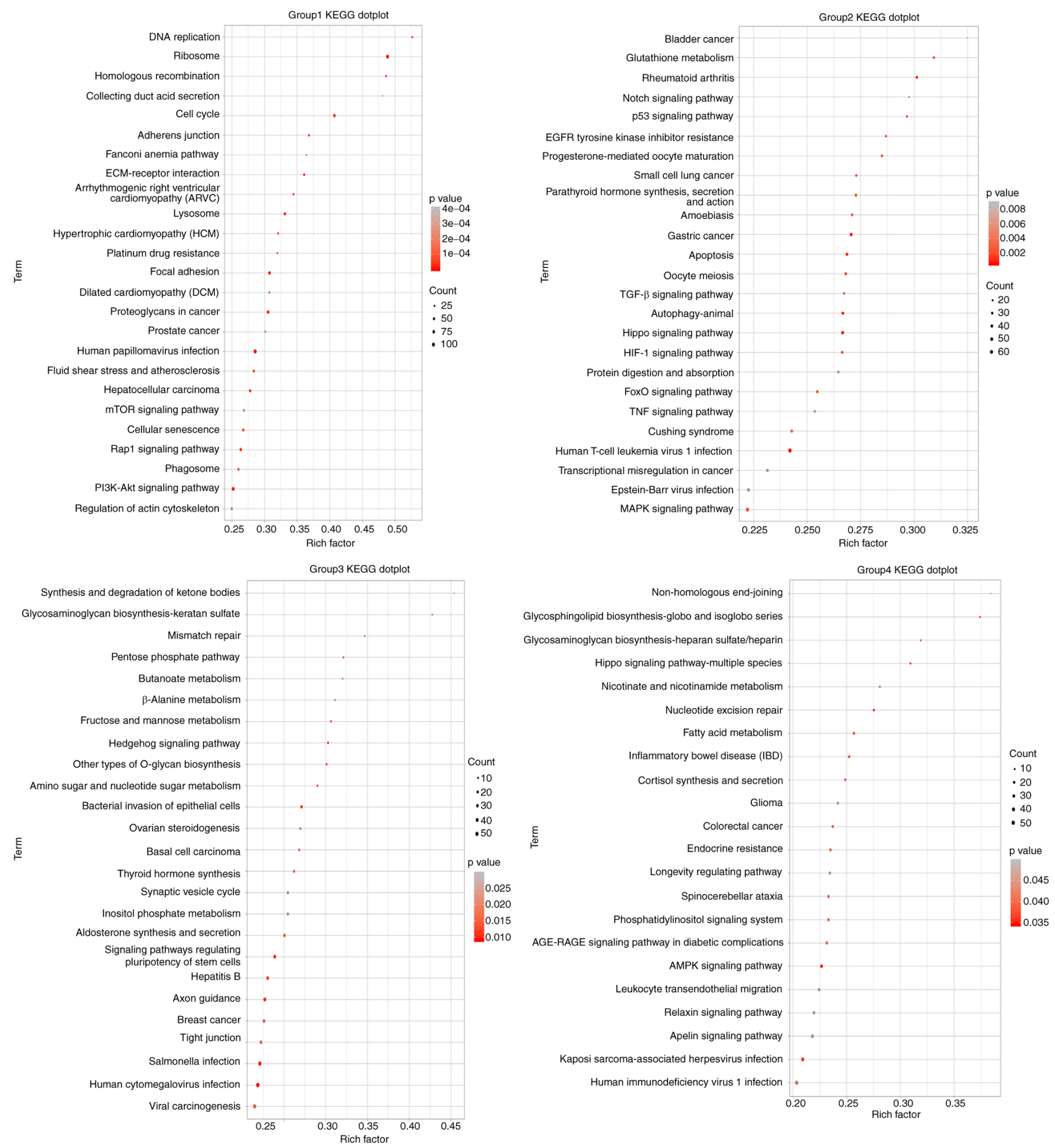

Figure 7. KEGG pathway analysis of DEGs. KEGG pathway enrichment analyses of DEGs for DRM vs. CTR. The color of the circle indicates the P-value and the size of the circle the number of DEGs. Large red circles indicate a higher enrichment of the pathway and number of DEGs in the pathway. DEGs, differentially expressed genes; DRM, doramectin; KEGG, Kyoto Encyclopedia of Genes and Genomes.

shown in Fig. 10D, compared with the CQ+DRM group, the expression levels of Ki-67, a marker of cell proliferation, were decreased in the DRM group. These results indicated that DRM-induced autophagy was involved in the reduction of tumor growth in a mouse xenograft model of GBM.

DRM-induced autophagy promotes apoptosis in vivo. To further detect the effect of DRM on autophagy in vivo, immunohistochemical staining and western blot analysis were performed. Immunohistochemical staining indicated that fewer p62-positive and more LC3-positive cells were observed in the tumors from DRM-treated mice compared with those from control mice (Fig. 11A). Similarly, western blot analysis revealed that the LC3I/LC3II protein was significantly elevated and P62 protein was significantly reduced in DRM-treated mice compared with the control mice (Fig. 11B). These results 


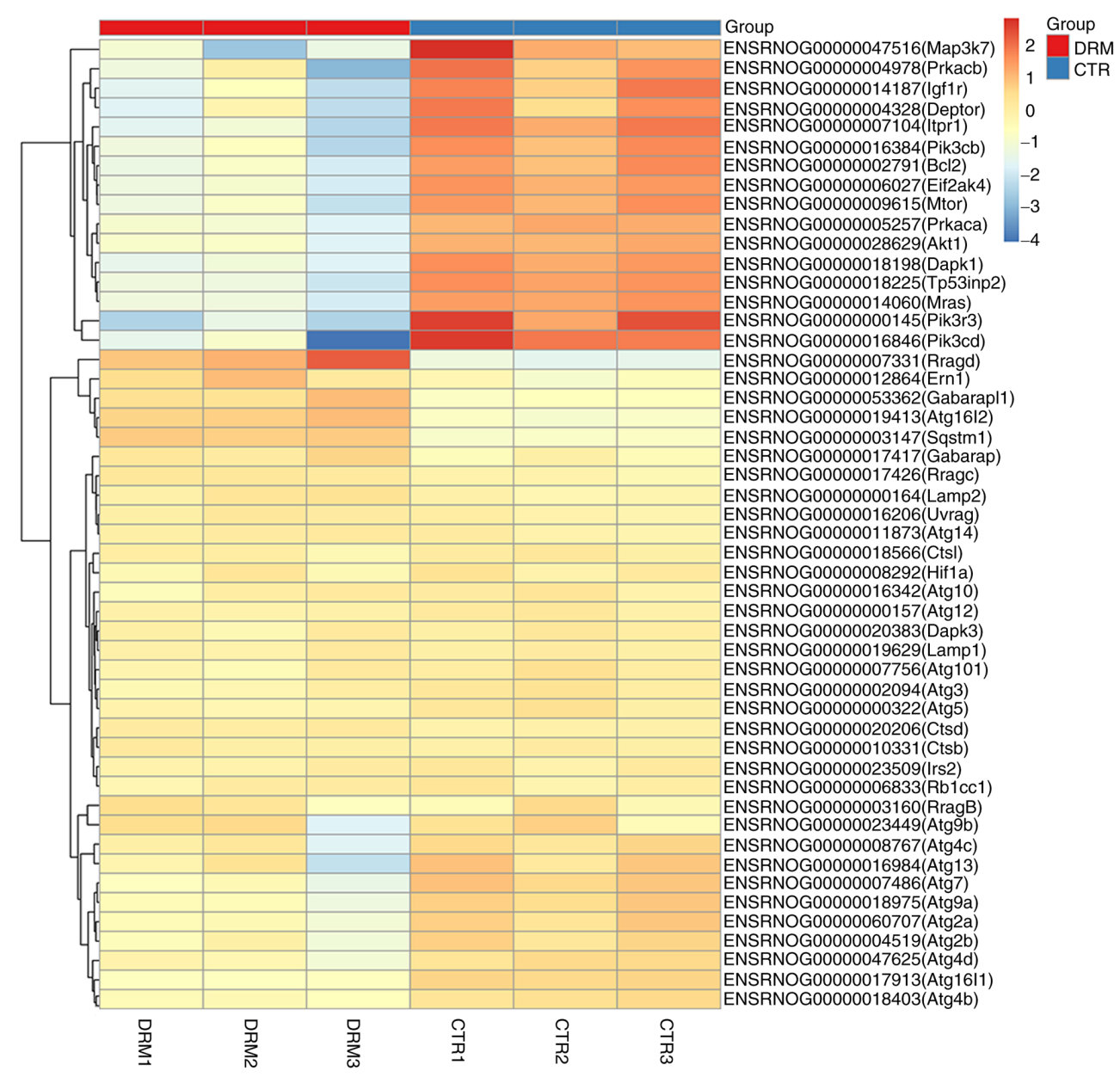

Figure 8. Heat map showing the expression fold changes of autophagy-related differentially expressed genes in DRM-treated C6 cells. CTR, control; DRM, doramectin.

demonstrated that treatment with DRM triggered autophagy in GBM cells in vivo. The association between DRM-induced autophagy and apoptosis was also explored in the nude mouse xenograft model. According to the TUNEL assay, an increased number of apoptotic cells were identified in the DRM-treated group compared with the CQ+DRM group (Fig. 11C), indicating that DRM-induced autophagy could enhance tumor apoptosis.

\section{Discussion}

The antitumor activity of macrocyclic lactones has been a research hotspot in recent years (44). Numerous studies have demonstrated that macrocyclic lactones inhibit the proliferation of cancer cells (45-47). In our previous study, it was demonstrated that IVM and AVM of the AVM family not only inhibited the proliferation of glioma cells via evoking apoptosis but also induced autophagy in glioma cells $(21,48)$. Furthermore, IVM has been used to treat filariasis and kill ixodesscapularis ticks feeding on humans (49). In the present study, DRM, a more effective and less toxic drug from the AVM family, was used to treat GBM. Different from studies on GBM and other macrocyclic drugs, the present study adopted other research methods to explore the effects of DRM on GBM. For instance, transcriptome analysis, which can explain the molecular mechanism of DRM-induced apoptosis and autophagy in GBM cells, was conducted. Whether DRM can induce autophagy of GBM cells remains to be studied further. The present study revealed that DRM induced autophagy in vitro and in vivo. In addition, DRM-induced autophagy served an important role in suppressing GBM cell proliferation. It was further demonstrated that DRM modulated a number of pathways and genes involved in autophagy, thereby affecting the initiation of autophagy.

In the present study, TEM and a GFP-LC3 transient transfection assay demonstrated that DRM not only induced the formation of autophagosomes but also induced the formation of a higher number of GFP-LC3 puncta on U87 and C6 cells. In addition, LC3 exists in both its soluble (LC3I) and autophagosome-related (LC3II) forms, and LC3I can transform into LC3II (40). The LC3II/LC3I ratio is used to assess the levels of autophagy $(41,42)$. During the process of autophagy, the p62 protein is involved in the conversion of LC3I to LC3II (50). As expected, DRM-induced autophagy was identified by western blot analysis, as revealed by the increase in LC3I/LC3II and the decrease in p62 protein expression. This result demonstrated that DRM can induce autophagy in GBM cells in vivo.

The functional relationship between autophagy and cell survival is complex, with recent evidence suggesting that 


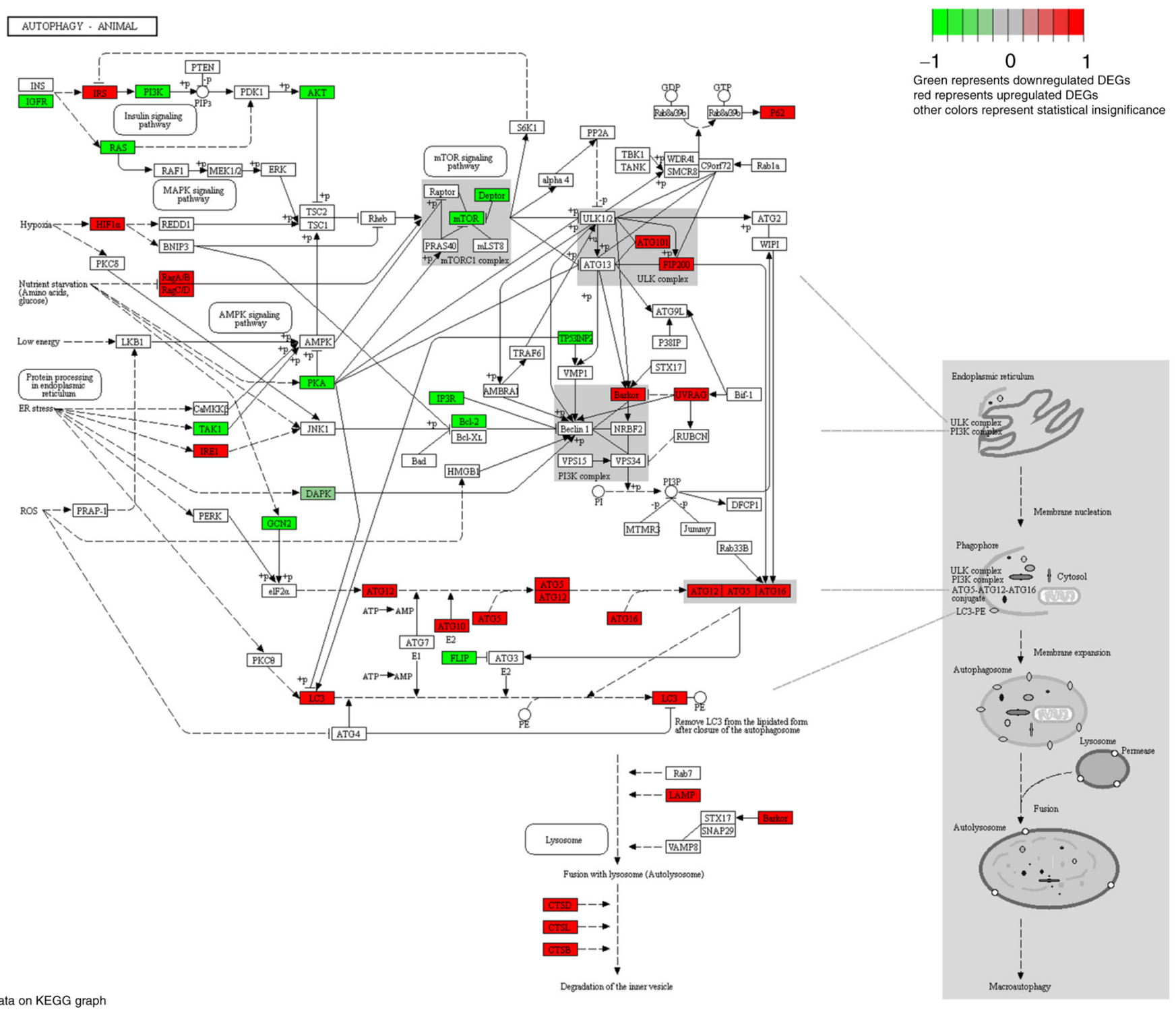

Figure 9. Autophagy pathway in C6 cells treated with doramectin $(15 \mu \mathrm{M})$. Expression changes of target genes are mapped by colors. Data on KEGG graph. Rendered by pathview. Green represents down regulated DEGs, red represents upregulated DEGs and other colors represent statistical insignificance. DEGs, differentially expressed genes.

A
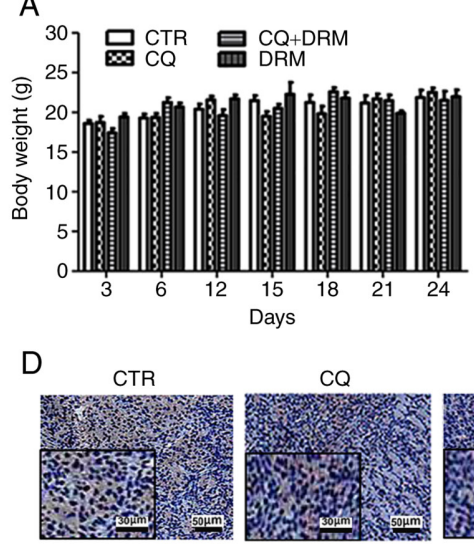

B

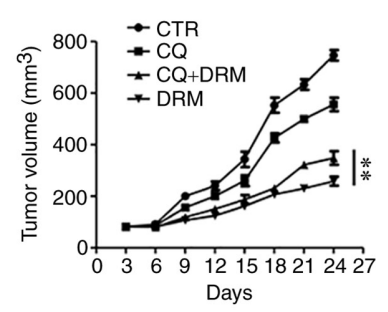

C
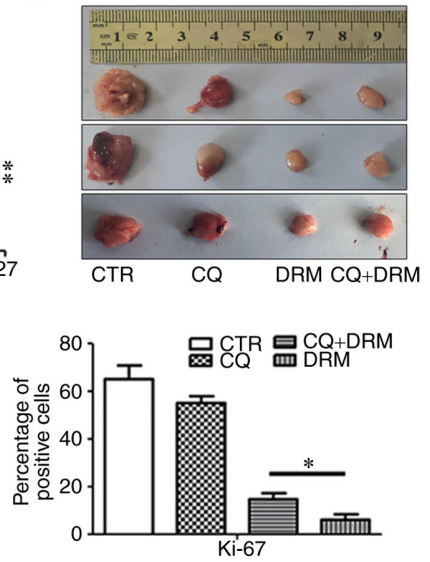

Figure 10. DRM suppresses tumor growth in vivo. (A) Body weight of nude mice treated with CTR, CQ, CQ+DRM and DRM. (B) Tumor growth curve of different treatment groups. (C) Size of tumors formed in different groups. (D) Immunohistochemical staining of C6 xenograft tumors was performed to detect Ki-67 expression following DRM treatment. Quantitative analysis of Ki-67-positive cells in xenograft tissues from different groups. Scale bar, 50 or $30 \mu \mathrm{m}$. Data are presented as the mean $\pm \mathrm{SD}, \mathrm{n} \geq 3$. ${ }^{*} \mathrm{P}<0.05$ and ${ }^{* *} \mathrm{P}<0.01$. CQ, chloroquine; CTR, control; DRM, doramectin. 
A

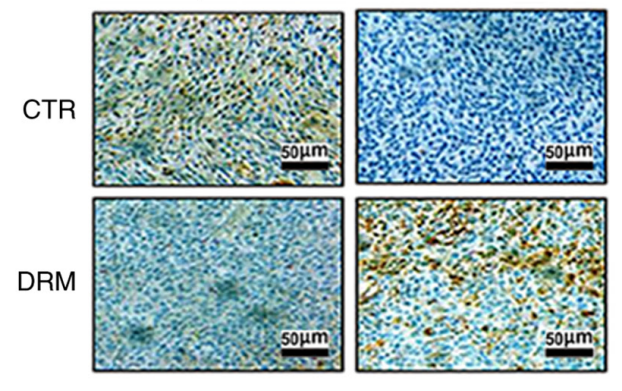

B

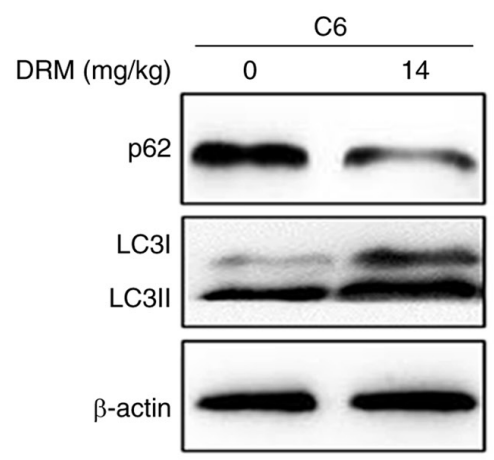

C
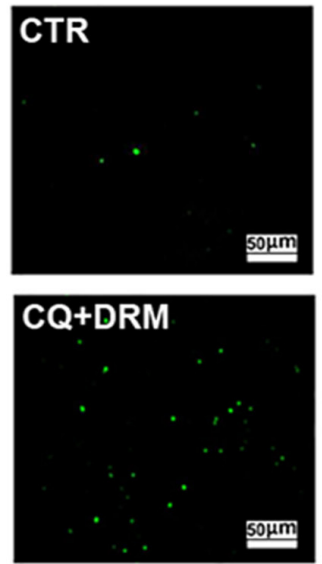
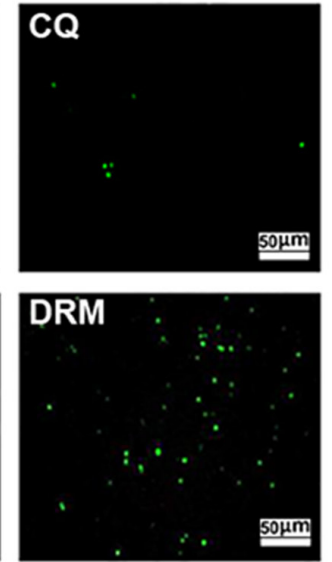
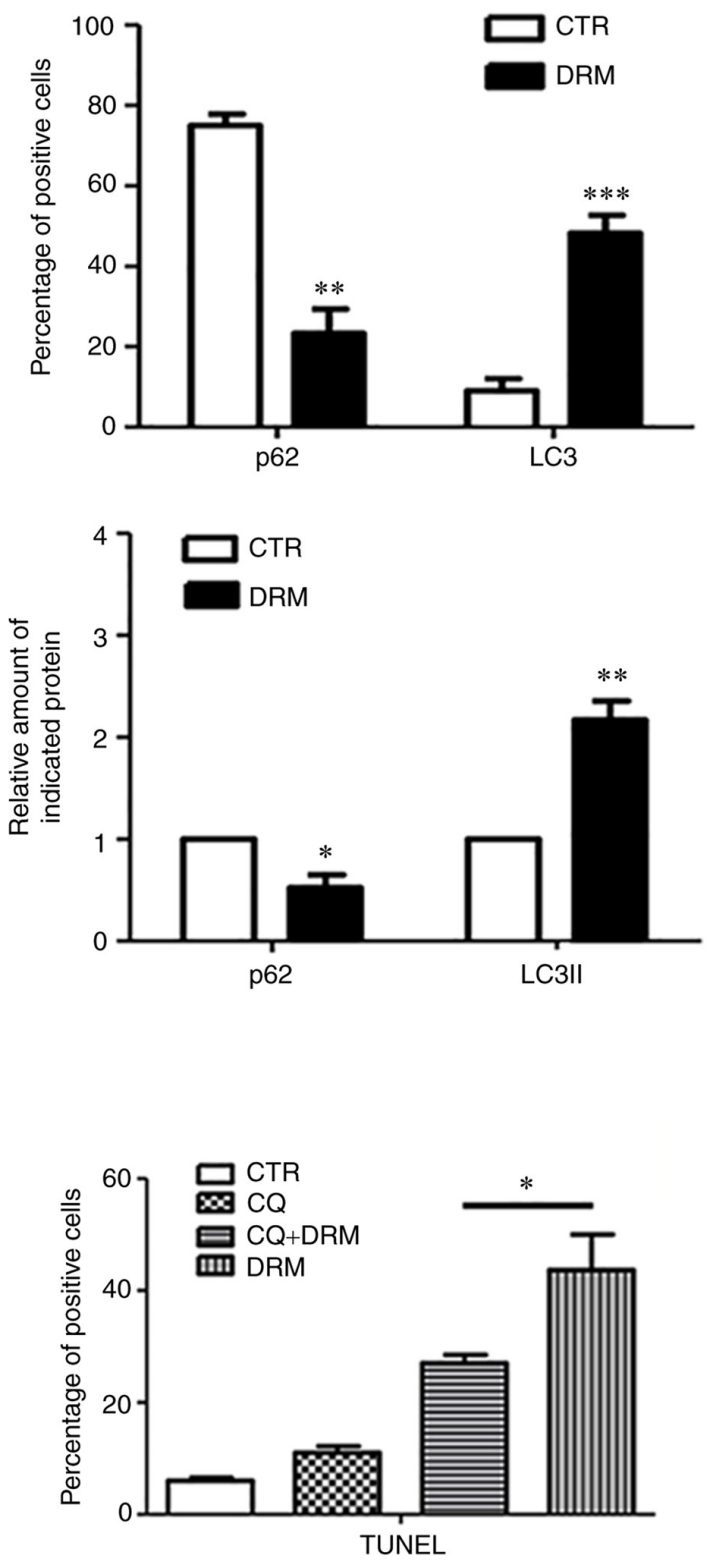

Figure 11. DRM induces autophagy and autophagy promotes apoptosis in vivo. (A) Immunohistochemical staining of C6 xenograft tumors was performed to detect the expression levels of p62 and LC3 following treatment with DRM. Quantitative analysis of p62- and LC3-positive cells in xenograft tissues from different groups was also performed. Scale bar, $50 \mu \mathrm{m}$. (B) C6 xenograft tumors were incubated with and without DRM, and the effects of DRM on the levels of p62 and LC3I/LC3II were examined by western blot analysis, and semi-quantitative analysis of p62 and LC3I/LC3II protein expression indifferent groups was performed. (C) A TUNEL assay was used to measure apoptotic C6 cells and calculate the apoptotic index of different groups. Quantitative analysis of positive cells in xenograft tissues from different groups was also performed. Scale bar, $50 \mu \mathrm{m}$. Data are presented as the mean $\pm \mathrm{SD}, \mathrm{n} \geq 3$. ${ }^{*} \mathrm{P}<0.05$, ${ }^{* *} \mathrm{P}<0.01$ and ${ }^{* * *} \mathrm{P}<0.001$ vs. control or as indicated. CQ, chloroquine; CTR, control; DRM, doramectin.

autophagy is a double-edged sword in cell death (51). On the one hand, it is considered an essential mechanism of protection and survival. On the other hand, it is also regarded as a type of programmed cell death $(52,53)$. However, the specific mechanism of the dual role of autophagy needs to be explored further. A study has reported that it is cell line-dependent (54). Some studies have suggested that different drugs had opposite effects in the same cell lines. For example, IVM-induced autophagy increased cell proliferation in glioma (48). However, 5 -methoxypsoralen induced glioma cell death by inhibiting autophagy (55). Therefore, DRM, a potential anticancer agent, is required to further explore the role of autophagy in cell death. In the present study, the autophagy inhibitor CQ was used to clarify the specific mechanisms involved in the effects of DRM-induced autophagy on GBM cells. When CQ enters the lysosome, it becomes protonated because of the low $\mathrm{pH}$ within the lysosome, and accumulation of the protonated form of chloroquine with in the lysosome leads to less acidic conditions and thereby decreased lysosomal function (56). First, autophagic flux assays demonstrated that CQ markedly increased LC3II expression in CQ-pretreated cells. In addition, MTT and colony formation assays were conducted to determine the effect of DRM-induced autophagy on inhibition of U87 and C6 cell viability and colony formation ratio. These 
results demonstrated that DRM-induced autophagy might be one of the reasons for the inhibition of proliferation in GBM cell lines.

It is well-known that the functional relationship between apoptosis and autophagy is complex (57). They suppress or promote one another or unilaterally promote or inhibit one another. Autophagy and apoptosis have been demonstrated to be interconnected by crosstalk between several molecular nodes (58). Research has demonstrated that Atg5 can be cleaved by calpain, which interacts with Bcl-XL and promotes cytochrome c release with caspase activation and apoptosis (59). The association between DRM-induced autophagy and apoptosis in GBM cells is not well understood, but the present study revealed that DRM induced GBM cell apoptosis via the mitochondria-dependent pathway, which is highly regulated by Bcl-2 family members. In addition, the present study demonstrated that DRM increased Atg5 protein expression, suggesting that DRM-induced autophagy can affect apoptotic changes. In order to clarify the association between autophagy and apoptosis, the autophagy inhibitor CQ was used to understand the role of DRM-induced autophagy in the apoptosis of U87 and C6 cells. Flow cytometry demonstrated that DRM-induced autophagy could increase the apoptotic rate in U87 and C6 cells. DAPI staining confirmed this conclusion. Therefore, it was demonstrated that DRM-induced autophagy promoted the increase in apoptosis in GBM cells.

The molecular mechanisms of the initiation of autophagy are not yet fully understood. However, a number of studies have demonstrated that numerous signaling pathways may be involved in the initiation of autophagy (60-62). Therefore, the regulation of the autophagy pathway was investigated using the KEGG database. mTOR was identified as a protein that serves a key regulatory role in the formation and maturation of autophagosomes, and the PI3K/AKT and AMP-activated protein kinase (AMPK) signaling pathways are also involved in the initiation of autophagy. In brief, a large number of genes are involved in regulating autophagy in cells. A transcriptome analysis was conducted on C6 cells to provide a genome-wide view of biological responses to DRM exposure. At the molecular level, transcriptome analysis revealed that a large number of significant DEGs were enriched in autophagy-related pathways. Autophagosome formation is dependent on the covalent attachment of a series of Atg proteins during protein ubiquitination $(43,63)$. It was demonstrated that DRM induced autophagy in GBM cells at the molecular level. KEGG analysis results demonstrated that a number of autophagy pathways were altered in the DRM group compared with the control group, including the autophagy-animal, PI3K/AKT, lysosome, phagosome, mTOR, MAPK, AMPK and DNA replication signaling pathways. Previously, the PI3K/AKT/mTOR pathway, as a critical regulator of autophagy, has been reported to be involved in the initiation and promotion of a series of pathological disorders in tumors (64). The PI3K/AKT/mTOR pathway was identified as the most enriched pathway in KEGG analysis, and the levels of PI3K, AKT and mTOR proteins were markedly reduced. This finding suggested that DRM-induced autophagy was mainly caused by the attenuation of PI3K/AKT/mTOR phosphorylation in GBM cells. Transcriptome analysis provided further evidence of DRM-induced autophagy. Our follow-up study will be based on the DEGs identified in the present study, which will serve as a foundation for exploring the other effects of DRM on GBM further.

To acquire more reliable evidence to support and verify the in vitro experimental findings, a xenograft nude mouse model was used to clarify the underlying molecular mechanisms of DRM autophagy in GBM cells in vivo. In the previous study, a subcutaneous injection of IVM was administered to a xenograft nude mouse model at a dose of $14 \mathrm{mg} / \mathrm{kg}$, and the toxicity was found to be acceptable and the dose safe $(19,45)$. Therefore, the same drug dosage was used in the in vivo experiment. A number of clinical trials have used CQ alone or in combination with other chemotherapies for the treatment of cancer $(65,66)$. In the present study, the effect of DRM+CQ was tested in a xenograft nude mouse model. The in vivo experiments revealed that the tumor volume was significantly smaller in the DRM group than in the DRM+CQ group. Immunohistochemical analysis of $\mathrm{Ki}-67$ activity also confirmed this conclusion. In addition, a TUNEL assay revealed that DRM-induced autophagy increased cell apoptosis in vivo. It was further demonstrated that DRM could induce autophagy in vivo. These findings were consistent with those of previous in vitro studies. Additionally, our research team has also examined the inhibitory effect of DRM on other tumors. For example, research has demonstrated that the inhibitory effect on breast cancer cells was not obvious (17). Esophageal cancer is inhibited by DRM (Li et al, unpublished data). Although DRM was found to have an effect on GBM cell proliferation and apoptosis in our previous experimental exploration (Chen et al, unpublished data), the lack of specific experimental data in this regard is a limitation of the present study. In future studies, the effects of DRM on GBM cells will be explored further to provide more data support for DRM as a novel drug for the treatment of cancer.

In conclusion, it was first demonstrated that DRM induced autophagy in U87 and C6 GBM cells in vitro and in vivo. In addition, the present study demonstrated that DRM altered a number of pathways involved in autophagy in C6 cells, and induced GBM cell autophagy mainly by blocking PI3K, AKT and mTOR at the molecular level. In addition, autophagy could inhibit GBM cell proliferation and apoptosis in vitro and in vivo. In combination, these findings provided a theoretical basis for the clinical application of DRM in the treatment of GBM.

\section{Acknowledgements}

The authors would like to thank Professor Saadia Khilji (Department of Cellular and Molecular Medicine, Faculty of Medicine, University of Ottawa, Ottawa, Ontario, Canada) for assisting in the preparation of the manuscript.

\section{Funding}

The present study was supported by the National Natural Science Foundation of China (grant no. 82071368), the Academic Backbone Foundation of Northeast Agricultural University (grant no. 19XG20) and the Outstanding Youth Funding of Harbin Medical University (grant no. HYD2020JQ0016). 


\section{Availability of data and materials}

The datasets generated and/or analyzed during the current study are available in the Sequence Read Archive repository (https://www.ncbi.nlm.nih.gov/bioproject/? term=PRJNA726037). Other data generated or analyzed during this study are included in this published article.

\section{Authors' contributions}

$\mathrm{CC}$ conceived and designed the project, interpreted the results and wrote the manuscript. AG, HL, RQ and XL conceived and designed the project and assisted in writing the manuscript. $\mathrm{CC}, \mathrm{LW}, \mathrm{SD}$ and $\mathrm{ZC}$ designed and performed the experiments. $\mathrm{XM}, \mathrm{ZL}, \mathrm{QW}$ and JM performed the statistical analysis, created the figures, and wrote and edited the manuscript. CC, AG and HL confirmed the authenticity of the raw data. All authors have read and approved the final manuscript.

\section{Ethics approval and consent to participate}

All procedures involving animals were performed in accordance with the ethical standards of the Harbin Weike Biotechnology research committee (Harbin Weike Biotechnology Co., Ltd., Harbin, China). All animal experiments conformed to the European Parliament Directive (2010/63/EU). The protocol was approved by the Management and Welfare of Experimental Animal Ethics Committee of Harbin Vic Biological Technology Development Co., Ltd. (approval no. JL-SD-0370; Harbin, China).

\section{Patient consent for publication}

Not applicable.

\section{Competing interests}

The authors declare that they have no competing interests.

\section{References}

1. Hanif F, Muzaffar K, Perveen K, Malhi SM and Simjee ShU: Glioblastoma multiforme: A review of its epidemiology and pathogenesis through clinical presentation and treatment. Asian Pac J Cancer Prev 18: 3-9, 2017.

2. Strom QT, Gittleman H, Xu J, Kromer C, Wolinsky Y, Kruchko C and Barnholtz-Sloan JS: CBTRUS statistical report: Primary brain and other central nervous system tumors diagnosed in the United States in 2009-2013. Neuro Oncol 18 (Suppl 5): v1-v75, 2016.

3. Louis DN, Ohgaki H, Wiestler OD, Cavenee WK, Burger PC, Jouvet A, Scheithauer BW and Kleihues P: The 2007 WHO classification of tumours of the central nervous system. Acta Neuropathol 114: 97-109, 2007.

4. Parsons DW, Jones S, Zhang X, Lin JC, Leary RJ, Angenendt P, Mankoo P, Carter H, Siu IM, Gallia GL, et al: An integrated genomic analysis of human glioblastoma multiforme. Science 321: 1807-1812, 2008.

5. Ohgaki H, Dessen P, Jourde B, Horstmann S, Nishikawa T, Di Patre PL, Burkhard C, Schüler D, Probst-Hensch NM, Maiorka PC, et al: Genetic pathways to glioblastoma: A population-based study. Cancer Res 64: 6892-6899, 2004.

6. Tykocki T and Eltayeb M: Ten-year survival in glioblastoma. A systematic review. J Clin Neurosci 54: 7-13, 2018.

7. Sathornsumetee S and Rich JN: Designer therapies for glioblastoma multiforme. Ann N Y Acad Sci 1142: 108-132, 2008.
8. Witthayanuwat S, Pesee M, Supaadirek C, Supakalin N, Thamronganantasakul K and Krusun S: Survival analysis of glioblastoma multiforme. Asian Pac J Cancer Prev 19: 2613-2617, 2018.

9. Preusser M, de Ribaupierre S, Wöhrer A, Erridge SC, Hegi M, Weller M and Stupp R: Current concepts and management of glioblastoma. Ann Neurol 70: 9-21, 2011.

10. Anjum K, Shagufta BI, Abbas SQ, Patel S, Khan I, Shah SA, Akhter N and Hassan SS: Current status and future therapeutic perspectives of glioblastoma multiforme (GBM) therapy: A review. Biomed Pharmacother 92: 681-689, 2017.

11. Stupp R, Hegi ME, Gilbert MR and Chakravarti A: Chemoradiotherapy in malignant glioma: Standard of care and future directions. J ClinOncol 25: 4127-4136, 2007.

12. Carson KA, Grossman SA, Fisher JD and Shaw EG: Prognostic factors for survival in adult patients with recurrent glioma enrolled onto the new approaches to brain tumor therapy CNS consortium phase I and II clinical trials. J Clin Oncol 25: 2601-2606, 2007.

13. Abe T, Mori T, Wakabayashi Y, Nakagawa M, Cole SP, Koike K, Kuwano $M$ and Hori S: Expression of multidrug resistance protein gene in patients with glioma after chemotherapy. J Neurooncol 40: 11-18, 1998.

14. Wang JB, Pan HX and Tang GL: Production of doramectin by rational engineering of the avermectin biosynthetic pathway. Bioorg Med Chem Lett 21: 3320-3323, 2011.

15. Murayama N, Shibata K and Nagata M: Efficacy of weekly oral doramectin treatment in canine demodicosis. Vet Rec 167: 63-64, 2010.

16. Taylor LF and Hodge A: Impact of a single treatment of injectable doramectin on weight gain post weaning in beef heifers and steers in central Queensland, Australia. Aust Vet J 97: 185-190, 2019.

17. Gao A, Wang X, Xiang W, Liang H, Gao J and Yan Y: Reversal of P-glycoprotein-mediated multidrug resistance in vitro by doramectin and nemadectin. J Pharm Pharmacol 61: 393-399, 2010.

18. Kramer L, Crosara S, Gnudi G, Genchi M, Mangia C, Viglietti A and Quintavalla C: Wolbachia, doxycycline and macrocyclic lactones: New prospects in the treatment of canine heartworm disease. Vet Parasitol 254: 95-97, 2018.

19. Ballweber LR and Baeten LA: Use of macrocyclic lactones in cattle in the USA. Curr Pharm Biotechnol 13: 1061-1169, 2012.

20. Melotti A, Mas C, Kuciak M, Lorente-Trigos A, Borges I and Ruiz i Altaba A: The river blindness drug ivermectin and related macrocyclic lactones inhibit WNT-TCF pathway responses in human cancer. EMBO Mol Med 6: 1263-1278, 2014.

21. Song D, Liang H, Qu B, Li YJ, Liu JJ, Zhang YN, Li L, Hu L, Zhang XT, Zhang X and Gao A: Ivermectin inhibits the growth of glioma cells by inducing cell cycle arrest and apoptosis in vitro and in vivo. J Cell Biochem 120: 622-633, 2019.

22. Zhang Y, Luo M, Xu W, Yang M, Wang B, Gao J, Li Y and Tao L: Avermectin confers its cytotoxic effects by inducing DNA damage and mitochondria-associated apoptosis. J Agric Food Chemm 64: 6895-6902, 2016.

23. Drinyaev VA, Mosin VA, Kruglyak EB, Novik TS, Sterlina TS, Ermakova NV, Kublik LN, Levitman MKh, Shaposhnikova VV and Korystov YN: Antitumor effect of avermectins. Eur J Pharmacol 501: 19-23, 2004.

24. Williams JC, Loyacano AF, DeRosa A, Gurie J, Clymer BC and Guerino F: Comparison of persistent anthelmintic efficacy of topical formulations of doramectin, ivermectin, eprinomectin and moxidectin against naturally acquired nematode infections of beef calves. Vet Parasitol 85: 277-288, 1999.

25. Rozali EN, Hato SV, Robinson BW, Lake RA and Lesterhuis WJ: Programmed death ligand 2 in cancer-induced immune suppression. Clin Dev Immunol 2012: 656340, 2012.

26. Hu J, Liu X, Hughes D, Esteva FJ, Liu B, Chandra J and Li S: Herceptin conjugates linked by EDC boost direct tumor cell death via programmed tumor cell necrosis. PLoS One 6: e23270, 2011.

27. Nordmann N, Hubbard M, Nordmann T, Sperduto PW, Clark HB and Hunt MA: Effect of gamma knife radiosurgery and programmed cell death 1 receptor antagonists on metastatic melanoma. Cureus 9: e1943, 2017.

28. Speidel D: Transcription-independent p53 apoptosis: An alternative route to death. Trends Cell Biol 20: 14-24, 2010.

29. Klionsky DJ, Abeliovich H, Agostinis P, Agrawal DK, Aliev G, Askew DS, Baba M, Baehrecke EH, Bahr BA, Ballabio A, et al: Guidelines for the use and interpretation of assays for monitoring autophagy in higher eukaryotes. Autophagy 4: 151-175, 2010. 
30. Kim KH and Lee MS: Autophagy-a key player in cellular and body metabolism. Nat Rev Endocrinol 10: 322-337, 2014.

31. Liao Y, Duan B, Zhang Y, Zhang X and Xia B: Excessive ER-phagy mediated by the autophagy receptor FAM134B results in ER stress, the unfolded protein response, and cell death in HeLa cells. J Biol Chem 294: 20009-20023, 2019.

32. Kim TW, Cheon C and Ko SG: SH003 activates autophagic cell death by activating ATF4 and inhibiting G9a under hypoxia in gastric cancer cells. Cell Death Dis 11: 717, 2020.

33. Klionsky DJ, Cuervo AM and Seglen PO: Methods for monitoring autophagy from yeast to human. Autophagy 3: 181-206, 2007.

34. Wang J, Qi Q, Zhou W, Feng Z, Huang B, Chen A, Zhang D, Li W, Zhang Q, Jiang Z, et al: Inhibition of glioma growth by flavokawain $B$ is mediated through endoplasmic reticulum stress induced autophagy. Autophagy 14: 2007-2022, 2018.

35. Howarth A, Madureira PA, Lockwood G, Storer LC, Grundy R, Rahman R, Pilkington GJ and Hill R: Modulating autophagy as a therapeutic strategy for the treatment of paediatric high-grade glioma. Brain Pathol 29: 707-725, 2019.

36. Liao Y, Smyth GK and Shi W: featureCounts: An efficient general purpose program for assigning sequence reads to genomic features. Bioinformatics 30: 923-930, 2014.

37. Maag JL: gganatogram: An R package for modular visualisation of anatograms and tissues based on ggplot2. F1000Res 7: 1576, 2018.

38. Sturn A, Quackenbush J and Trajanoski Z: Genesis: Cluster analysis of microarray data. Bioinformatics 18: 207-208, 2002.

39. Yu G, Wang LG, Han Y and He QY: ClusterProfiler: An R package for comparing biological themes among gene clusters. OMICS 16: 284-287, 2012.

40. Tanida I, Ueno T and Kominami E: LC3 and autophagy. Methods Mol Biol 445: 77-88, 2008.

41. Onorati AV, Dyczynski M, Ojha R and Amaravadi RK: Targeting autophagy in cancer. Cancer 124: 3307-3318, 2018

42. Tanida I, Ueno T and Kominami E: LC3 conjugation system in mammalian autophagy. Int J Biochem Cell Biol 36: 2503-2518, 2004

43. Mizushima N, Yoshimori T and Ohsumi Y: The role of Atg proteins in autophagosome formation. Annu Rev Cell Dev Biol 27: 107-132, 2011.

44. Gallardo F, Mariamé B, Gence R and Tilkin-Mariamé AF: Macrocyclic lactones inhibit nasopharyngeal carcinoma cells proliferation through PAK1 inhibition and reduce in vivo tumor growth. Drug Des Devel Ther 12: 2805-2814, 2018.

45. Markowska A, Kaysiewicz J, Markowska J and Huczyński A: Doxycycline, salinomycin, monensin and ivermectin repositioned as cancer drugs. Bioorg Med Chem Lett 29: 1549-1554, 2019.

46. Juarez M, Schcolnik-Cabrera A and Duenas-Gonzalez A: The multitargeted drug ivermectin: From an antiparasitic agent to a repositioned cancer drug. Am J Cancer Res 8: 317-331, 2018.

47. Zhang X, Zhang G, Zhai W, Zhao Z, Wang S and Yi J: Inhibition of TMEM16A Ca2+-activated Cl- channels by avermectins is essential for their anticancer effects. Pharmacol Res 156: 104763, 2020.

48. Liu J, Liang H, Chen C, Wang X, Qu F, Wang H, Yang K, Wang Q, Zhao N, Meng J and Gao A: Ivermectin induces autophagy-mediated cell death through the AKT/mTOR signaling pathway in glioma cells. Biosci Rep 39: BSR20192489, 2019.

49. Sheele JM, Ford LR, Tse A, Chidester B, Byers PA and Sonenshine DE: The use of ivermectin to kill ixodesscapularis ticks feeding on humans. Wilderness Environ Med 25: 29-34, 2014.

50. Klionsky DJ, Abdalla FC, Abeliovich H, Abraham RT, Acevedo-Arozena A, Adeli K, Agholme L, Agnello M, Agostinis P, Aguirre-Ghiso JA, et al: Guidelines for the use and interpretation of assays for monitoring autophagy. Autophagy 8: 445-544, 2012.
51. Xin $\mathrm{P}, \mathrm{Xu} \mathrm{W}$, Zhu X, Li C, Zheng Y, Zheng T, Cheng W and Peng Q: Protective autophagy or autophagic death: Effects of BEZ235 on chronic myelogenous leukemia. Cancer Manag Res 11: 7933-7951, 2019.

52. Pyo JO, Yoo SM, Ahn HH, Nah J, Hong SH, Kam TI, Jung S and Jung YK: Overexpression of Atg5 in mice activates autophagy and extends lifespan. Nat Commun 4: 2300, 2013.

53. Levy JM, Towers CG and Thorburn A: Targeting autophagy in cancer. Nat Rev Cancer 17: 528-542, 2017.

54. Baehrecke EH: Autophagy: Dual roles in life and death? Nature Rev Mol Cell Biol 6: 505-510, 2005.

55. Guo H, He Y, Bu C and Peng Z: Antitumor and apoptotic effects of 5-methoxypsoralen in U87MG human glioma cells and its effect on cell cycle, autophagy and PI3K/Akt signaling pathway. Arch Med Sci 15: 1530-1538, 2019.

56. Mauthe M, Orhon I, Rocchi C, Zhou XD, Luhr M, Hijlkema KJ, Coppes RP, Engedal N, Mari M and Reggiori F: Chloroquine inhibits autophagic flux by decreasing autophagosome-lysosome fusion. Autophagy 14: 1435-1455, 2018.

57. Lalaoui N, Lindqvist LM, Sandow JJ and Ekert PG: The molecular relationships between apoptosis, autophagy and necroptosis. Semin Cell Dev Biol 39: 63-69, 2015.

58. Maiuri MC, Zalckvar E, Kimchi A and Kroemer G: Self-eating and self-killing: Crosstalk between autophagy and apoptosis. Nat Rev Mol Cell Biol 8: 741-752, 2007.

59. McCoy F, Hurwitz J, McTavish N, Paul I, Barnes C, O'Hagan B, Odrzywol K, Murray J, Longley D, McKerr G and Fennell DA: Obatoclax induces Atg7-dependent autophagy independent of beclin-1 and BAX/BAK. Cell Death Dis 1: e108, 2010

60. Lin JZ, Wang WW, Hu TT, Zhu GY, Li LN, Zhang CY, Xu Z, Yu HB, Wu HF and Zhu JG: FOXM1 contributes to docetaxel resistance in castration-resistant prostate cancer by inducing AMPK/mTOR-mediated autophagy. Cancer Lett 469: 481-489, 2020.

61. Liu JZ, Hu YL, Feng Y, Guo YB, Liu YF, Yang JL, Mao QS and Xue WJ: Rafoxanide promotes apoptosis and autophagy of gastric cancer cells by suppressing PI3K/Akt/mTOR pathway. Exp Cell Res 385: 111691, 2019.

62. Ding R, Wang X, Chen W, Li Z, Wei AL, Wang QB, Nie AH and Wang LL: WX20120108, a novel IAP antagonist, induces tumor cell autophagy via activating ROS-FOXO pathway. Acta Pharmacol Sin 40: 1466-1479, 2019.

63. Tsuboyama K, Koyama-Honda I, Sakamaki Y, Koike M, Morishita $\mathrm{H}$ and Mizushima N: The ATG conjugation systems are important for degradation of the inner autophagosomal membrane. Science 354: 1036-1041, 2016

64. Xu Z, Han X, Ou D, Liu T, Li Z, Jiang G, Liu J and Zhang J: Targeting PI3K/AKT/mTOR-mediated autophagy for tumor therapy. Appl Microbiol Biotechnol 104: 575-587, 2020.

65. Höglund R, Moussavi Y, Ruengweerayut R, Cheomung A, Äbelö A and Na-Bangchang K: Population pharmacokinetics of a three-day chloroquine treatment in patients with Plasmodium vivax infection on the Thai-Myanmar border. Malar J 15: 129, 2016.

66. Maycotte P, Aryal S, Cummings CT, Thorburn J, Morgan MJ and Thorburn A: Chloroquine sensitizes breast cancer cells to chemotherapy independent of autophagy. Autophagy 8: 200-212, 2012.

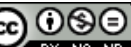

This work is licensed under a Creative Commons Attribution-NonCommercial-NoDerivatives 4.0 International (CC BY-NC-ND 4.0) License. 